Seton Hall University eRepository@Seton Hall

Seton Hall University Dissertations and Theses (ETDs)

Seton Hall University Dissertations and Theses

Spring 5-22-2017

\title{
The Lived Experience of Chemo Brain in Early Stage Breast Cancer in Women 50 and Under
}

Patricia A. Gibbons

patricia.gibbons@student.shu.edu

Follow this and additional works at: https://scholarship.shu.edu/dissertations

Part of the Medical Education Commons, and the Other Nursing Commons

\section{Recommended Citation}

Gibbons, Patricia A., "The Lived Experience of Chemo Brain in Early Stage Breast Cancer in Women 50 and Under" (2017). Seton Hall University Dissertations and Theses (ETDs). 2295.

https://scholarship.shu.edu/dissertations/2295 


\title{
THE LIVED EXPERIENCE OF CHEMO BRAIN IN EARLY STAGE BREAST CANCER IN WOMEN 50 AND UNDER
}

\author{
PATRICIA A. GIBBONS
}

\author{
Dissertation Committee
}

Dr. Judith Lothian, Chair

Dr. Bonnie Sturm

Dr. Munira Wells

Submitted in partial fulfillment of the

Requirements for the degree of Doctor of Philosophy in Nursing

Seton Hall University

2017 
Copyright (C) Patricia A. Gibbons 2017 
THE LIVED EXPERIENCE OF CHEMO BRAIN IN EARLY

\section{STAGE BREAST CANCER IN WOMEN 50 AND UNDER}

BY

PATRICIA A. GIBBONS

Dissertation Committee

Dr. Judith Lothian, Chair

Dr. Bonnie Sturm

Dr. Munira Wells

Approved by Dissertation Committee

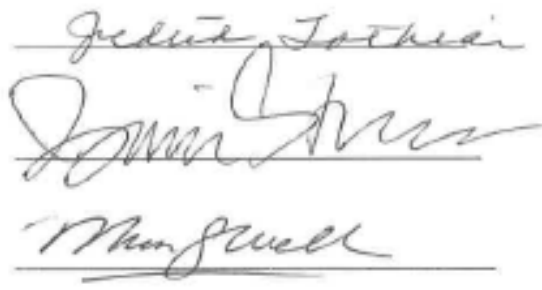
Date $3,13,17$
Date $3-13-17$
Date $3-13-17$

Submitted in partial fulfillment of the

Requirements for the degree of Doctor of Philosophy in Nursing.

Seton Hall University 


\section{Acknowledgements}

I would like to take this opportunity to thank the six women who agreed to participate in this study. I am so grateful to them for being so candid about their experiences with chemo brain. Because I gave them a forum to speak about their experiences, I was able to gain a deeper understanding of what chemo brain meant to them. I will be forever thankful for their bravery and willingness to share their time and veracity with me.

I would also like to acknowledge the local ONS chapters who allowed me to speak at their monthly meetings in hopes of gaining participants. Although I was not able to obtain any participants, I am still grateful for the opportunity. I was able to secure participants through colleagues and friends who helped to spread the word about my research. Without their help I would still be looking for participants.

I would be remiss if I did not mention my coworkers as well as two people who also helped to make this dissertation possible. Both Valentina Kloosterman and Julie Schantz provided me with support to make this happen. Valentina helped to keep me on track when I did not know how to proceed while Julie lit a fire under me during the final process. Both kept me from losing steam and I will be forever grateful. 
I am so grateful to my committee members, Dr. Bonnie Sturm and Dr. Munira Wells and especially to my chairperson, Dr. Judith Lothian who was always so supportive and caring. She helped me to believe that I could achieve my goals when I was struggling along. She gave me strength and motivation when I needed it most and I am so thankful to have had her as my advisor and mentor. 


\section{Dedication}

This dissertation is dedicated to my wonderful family and friends who provided unconditional support throughout the dissertation process. Between driving me to class when I didn't have a car, providing me with meals when I didn't have time to prepare them, and later with babysitting so that I could have time to work on my dissertation, my family and dear friends were my number one support system. They encouraged me throughout my scholarly journey and helped to keep me on track even when I was losing steam. Without them, this journey would not have been possible. 
Table of Contents

LIST OF TABLES...............................................................10

LIST OF FIGURES......................................................11

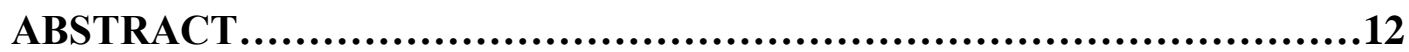

\section{CHAPTER}

I. INTRODUCTION

Problem........................................................13

Problem Statement.............................................15

Assumptions.................................................16

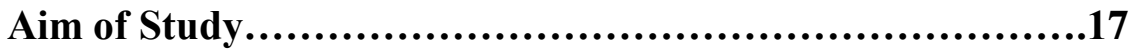

Research Method................................................17

Research Question.................................................17

Relevance to Nursing........................................17

\section{REVIEW OF THE LITERATURE}

Historical Perspective.............................................21

Experiential Context.............................................21

Gaps in the Literature.........................................22

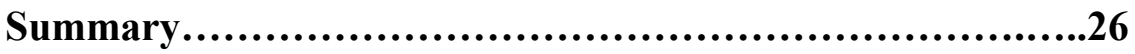

\section{METHODOLOGY}

Rationale for Choosing Method................................27 
Background....................................................27

Translation of Concepts and Terms............................28

General Steps...................................................28

\section{APPLIED METHODOLOGY}

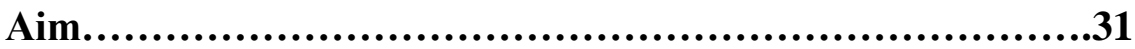

Participants......................................................31

Setting.........................................................33

Gaining Access and Establishing Rapport.....................33

General Steps in Data Collection................................35

Analysis.......................................................36

Establishing and Maintaining Trustworthiness.................36

Researcher Stance.............................................40

Protection of Human Subjects..................................41

\section{PARTICIPANT PROFILES}

Carol...............................................................43

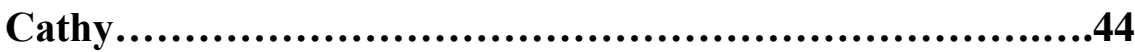

Julie..............................................................45

Sheila...............................................................47

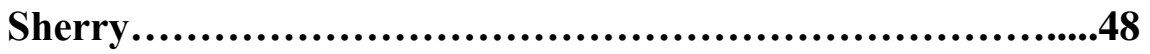

Tina..................................................................50 
VI. RESEARCH FINDINGS

Struggles with Day to Day Life...............................53

Overwhelming Fatigue..........................................60

Emotions Related to Diagnosis and Treatment................61

Coping and Support..........................................65

Feeling Grateful................................................69

\section{DISCUSSION, IMPLICATIONS, AND RECOMMENDATIONS}

Discussion......................................................71

Implications for Nursing....................................76

Recommendations for Future Research.......................78

Final Thoughts.................................................79

VIII. REFERENCES.....................................................81

\section{APPENDICES}

A. van Manen's Method of Phenomenology..................85

B. Flyer.........................................................87

C. Consent Form...........................................88

D. Letter of Invitation to Nurses From Local Practices.......92

E. Permission to Invite Local..................................94

F. Permission to Speak at Local ONS Chapters...............95

G. List of Support Groups................................97

H. Interview Outline/Guidelines..............................99 


\section{LIST OF TABLES}

1. Participant Profiles................................................32

2. Signs/Symptoms of Chemo Brain ...................................77

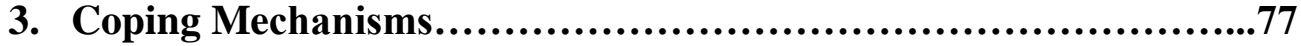

4. What Women Want to Know.....................................78 


\section{LIST OF FIGURES}

1. Connection Between the Emerged Themes and Chemo Brain..........52

2. Sub-themes Related to Struggles with Day to Day Life................53 


\begin{abstract}
Cognitive deficits have been shown to affect those who have undergone treatment with chemotherapy. This is often referred to as chemo-brain. The purpose of this descriptive phenomenological study was to explore the lived experience of the chemo brain after undergoing chemotherapy for breast cancer. The study sample consisted of six women between the ages of 29 and 50 with early stage breast cancer. van Manen's (1997) descriptive phenomenological method guided data analysis. The recurrent themes identified in this study were (1) Struggles with day to day life (2) Emotions related to diagnosis and treatment, (3) Fatigue (4) Coping and support, and (5) Feeling grateful. Findings of this study confirm the existence of cognitive changes during and after chemotherapy and describe as well the effects on daily life including fatigue, emotions, and the importance of support. This study suggests the importance of educating both healthcare providers and patients about the cognitive changes related to chemotherapy and ways to cope with these changes.
\end{abstract}




\section{Chapter I}

\section{Introduction}

I was so relieved to have finished the breast surgery 3 months ago, but I never dreamed I would have such a hard time with the chemotherapy. I have no problem with the nausea, or even the hair loss, but I feel like I am losing my mind. I can't remember anything anymore. I forgot to pick my daughter up from her friend's house the other day. I felt so awful. I went shopping in the mall and couldn't remember where I put my car. It took me over an hour and a half to find it. I had to have security help me find it. I was so frustrated! I have to leave notes all over my kitchen just to remind myself to do the things I always do so easily without thinking about it. Is there anything that can help my chemo brain? (M.E. Henitz, personal communication, October 4, 2009).

\section{Problem}

Chemo brain refers to cognitive changes associated with cancer treatment (Staat \& Segatore, 2005). It has been reported in up to $90 \%$ of women undergoing chemotherapy for breast cancer (Pullens, De Vries, \& Roukema, 2010). According to Staat and Segatore, (2005), women who have experienced chemo brain describe it as an inability to concentrate, remember details, and complete familiar tasks as quickly as they had done prior to their cancer diagnosis and treatment. Symptoms associated with chemo brain include; complaints of short term memory loss, difficulty concentrating, struggling to make simple decisions, difficulty finding the right words, trouble multi-tasking and feelings of mental dullness (Staat \& Segatore, 2005). 
Researchers use different terminology, for example, cognitive impairment or chemo fog, to discuss the phenomenon of chemo brain, offer many factors to explain it, and use various tools to evaluate the different cognitive processes that are affected (Hess \& Insel, 2007).

Although there are anecdotal accounts from healthcare providers, there is only minimal qualitative research that describes women's experiences with chemo brain. According to Staat and Segatore (2005), specific elements of thinking or cognitive function that can be negatively affected by chemo brain include language ability, memory, concentration, and attention. Hindsight, foresight, and judgment can also be affected. Jenkins, Shilling, Deutsch, Bloomfield, Morris, Allen et al. (2006) describe chemo brain as having feelings of fuzzy headedness, or mental slowness, and patients who experience it often complain about weakened cognitive abilities, such as a diminution of their usual speed in processing information, poor reaction time and poor organizational skills. Patients offer examples such as not being able to remember where they put their keys, parked their cars, or who wrote the book they just finished reading (Staat and Segatore, 2005). Others complain they have trouble finding the right words to describe everyday things, such as a calculator, or a pencil (Harvard Health Publications, 2002). In research using a case study method, cognitive dysfunction associated with chemotherapy was found to affect the ability of women with breast cancer to maintain usual family, career, and community responsibilities (Pareska \& Bender, 2003).

The Oncology Nursing Society (ONS) emphasizes the importance of the study of cancer symptoms and the side effects of treatment measures as a priority for research. They are particularly interested in neurological effects that include cognitive impairment and mental status 
changes (ONS Research Agenda, 2005). Healthy People 2010 and 2020 cite increasing quality and years of a healthy life as one of its main, national healthcare goals and additionally, has named cancer related issues as a major research focus. The aim is to reduce the number of new cancer cases, as well as the illnesses, disabilities, and deaths caused by cancer (U.S. Department of Health and Human Services [DHHS], 2017). Chemo brain, as a result of chemotherapy treatment of women diagnosed with breast cancer, is an important, and little understood phenomena both for the women using the healthcare system and for the professional nurses who are their major healthcare providers (Frank, Vance, Jukkala, \& Meneses, 2014). Symptoms of chemo brain that significantly impact the quality of life for women with breast cancer who are receiving chemotherapy are evident in their daily lives; however, patients with manifestations of chemo brain often do not receive validation, treatment or education about these symptoms (Grober, 2002). Although chemo brain is reported in up to $90 \%$ of women receiving chemotherapy treatment for breast cancer, depth of knowledge related to it is lacking (Pullens, De Vries, \& Roukema, 2010). Learning about the experience of chemo brain may ultimately improve the lives of women who experience it.

\section{Problem Statement}

The literature fails to provide a clear research based understanding of the phenomenon of chemo brain. Although there are anecdotal reports of chemo brain and many quantitative studies on symptoms and underlying pathophysiology, there is no research describing women's experience of chemo brain. In 1998, Frits. van Dam, Schagen, Muller, Droogleever Fortuyn, Wall, and Rodenhuis, studied the long term effects of high-dose chemotherapy versus standard 
dose therapy and found that cognitive deficits such as problems with memory and concentration were not uncommon after chemotherapy but were not systematically documented. Chemo brain today is still not clearly documented. Qualitative studies are limited, but two studies by Thielen (2008) and Mulrooney (2007) discussed chemo brain in breast cancer. Both studied neurocognitive dysfunction in women with breast cancer that included a population of women with similar socioeconomic and educational backgrounds as well as similar age ranges (up to 75 years). Another qualitative study by Rust and Davis (2013) looked specifically at chemo brain in underserved African American breast cancer survivors. There is no qualitative research exploring chemo brain in women 50 and under who experience it, and since normal aging affects, visual and verbal memory, the ability to think, visuospatial abilities, immediate memory, and the ability to name objects (Gazzaley, 2010), this area needs to be further explored in younger women. Therefore, there is a need to initiate inquiry that will provide understanding of chemo brain from the perspective of women 50 and under who are experiencing it.

\section{Assumptions}

In my clinical experience in the private practice setting, I have seen many women with early stage breast cancer who have experienced chemo brain as result chemotherapy, but not every patient was affected by it. With the advancement of technology, breast cancer can be detected earlier and the overall cure and survival rates have greatly increased (American Cancer Society, 2015). I cannot tell which woman will have symptoms of cognitive dysfunction prior to starting chemotherapy. Although I may not be able to identify who will succumb to chemo brain, I hope to gain a better understanding of what this experience involves. The type of treatment, 
menopausal status, or age of the woman does not seem to affect who will develop symptoms of chemo brain. Patients often complain about feeling fuzzy-headed and make jokes about chemo brain, but it is difficult to assess exactly what it is, let alone treat it.

\section{Aim of the Study}

The aim of the study is to describe the lived experience of chemo brain for women 50 years of age and younger with early stage breast cancer.

\section{Research Method}

Phenomenology explores the lived experience; therefore phenomenology was used to describe the lived experience of chemo brain for women 50 and younger with early stage breast cancer. The participants were women with early stage breast cancer who were currently experiencing or had symptoms of self-reported chemo brain in the last six months prior to the study. They were studied in order to get a sense of what chemo brain means to them and the impact that it had on their lives.

\section{Research Question}

What is the lived experience of chemo brain for women 50 and younger with early stage breast cancer?

\section{Relevance to Nursing}

Chemo brain is an important phenomenon for the discipline of nursing. Most oncology nurses have heard something about chemo brain, but they do not really know what it is or how to treat it. In discussing symptom management, nurses and doctors may briefly mention chemo brain to patients, but they cannot completely explain this concept, much less offer interventions 
for these particular symptoms, as they can for other side effects of chemotherapy. Healthcare practitioners can offer anti-nausea medications for nausea and vomiting, laxatives and stool softeners for constipation, growth factors for anemia, neutropenia and thrombocytopenia, and pain medication for pain, but there are currently no evidence based interventions substantiated by research used to treat chemo brain, and many of the neuropsychological testing that is used to confirm patient reports of chemo brain is not representative of the individual's home and work environment ( Meyer, 2013). Because of the great strides made in the diagnosis and treatment of cancer in general, cancer has become a chronic condition. Patients live longer with their diagnoses, continue to carry out their usual activities of daily living and remain in the workforce throughout their chemotherapy regimen (Olin, 2001). Chemo brain can impact the productivity of the labor force. Patients with chemo brain may not be as productive as they were prior to receiving chemotherapy. They may have to spend more time on tasks because they cannot remember details that they once took for granted. This comes at a cost to the patients who experience it, the nurses who treat them and to society. The Oncology Nursing Society (ONS Research Agenda, 2005) and Healthy People 2010 and 2020 identify the study of neurological effects of chemotherapy (including cognitive dysfunction) as a priority research area for nurses. 


\section{Chapter II}

\section{Review of Literature}

The American Cancer Society (ACS) estimated that 231,840 new cases of invasive breast cancer were reported in 2015, which means that about 1 in 8 women will develop breast cancer this year (ACS, 2015). Chemo brain has been reported in $90 \%$ of women undergoing chemotherapy for breast cancer (Pullens, De Vries, \& Roukema, 2010), but there are gaps in the overall understanding and assessment of it. The vague phenomenon of chemo brain has been explained in the literature by different factors, terms, and tools used to evaluate different cognitive processes (Hess \& Insel, 2007). Despite these differences, all agree that chemo brain exists and is a problem for both patients whose usual lifestyle is negatively affected, as well as healthcare providers who feel uncertain as to how to intervene.

According to Staat and Segatore (2005), cognitive functions like language ability, memory, concentration, judgment, and attention can be negatively affected by chemotherapy. Patients describe chemo brain as being mentally slow as evidenced by lack of speed in processing information, having poor organizational skills, and having poor reaction time (Jenkins et al., 2006). They offer examples such as not being able to remember who their favorite author is, where they parked their car in the mall, and where they put their keys (Staat and Segatore, 2005). They may also have trouble finding the right words to describe everyday things, such as a calculator, or a pencil (Harvard Health Publication, 2002). Cognitive dysfunction associated with chemotherapy can affect the ability of women with breast cancer to maintain their usual daily 
responsibilities (Pareska \& Bender, 2003, Kennedy, Haslam, Munir, and Pryce (2007), Munir, Burrows, Yarker, Kalawsky and Bains (2010) Hede (2008).

Inagaki, et al., 2006, have concluded that adjuvant chemotherapy causes neurochemical changes in the brain and can influence brain structure which may account for previously observed cognitive impairments. In addition, chemotherapeutic agents such as cyclophosphamide, adriamycin, methotrexate, fluorouracil, epirubicin, and paclitaxol, although once thought to have little ability to penetrate the blood-brain barrier, have been found in higher concentrations than expected in cerebrospinal fluid and brain tissue (Inagaki, et al, 2006). These drugs are hypothesized to have neurotoxic potential by interfering with DNA and RNA synthesis and function, inhibition of microtubule formation, and/or immunosuppressive properties (Inagaki, et al, 2006).

Similarly, Jansen, Miaskowski, Dodd, Dowling, and Kramer (2005) also found that some chemotherapeutic agents affect neuroanatomic structures which can have an effect on cognitive function. These researchers found that neurotoxicity associated with specific chemotherapies can be caused by leukoencephalopathy, cytokine-induced inflammatory response in brain tissue, chemotherapy-induced anemia affecting oxygen carrying ability of the blood, and chemotherapyinduced menopause that triggers hormone imbalances. Each of these changes may affect the overall structure and function of the brain and result in chemo brain. 
Historical Perspective

Chemo brain was first identified in 1980 by Silberfarb, Philbert, and Levine. They highlighted the potential side effects of chemotherapy on cognition. Their aim was to discover and document early neurocognitive changes in medical oncology patients in order to determine if these side effects were relevant factors in patient care. Research on the phenomenon of chemo brain in breast cancer did not begin until the mid to late 1990's when Weineke and Dienst (1995) used a retrospective study design to evaluate cognitive function in 28 women with stage I and II breast cancer. Most of the research that took place since then has focused on the many tools used to evaluate all of the different cognitive processes. Although a variety of quantitative designs have been used to elucidate the breast cancer experience of women, only a few qualitative nursing studies have been found that exclusively focus on the side effects of chemotherapy that are particular to the phenomenon of chemo brain (Thielen, 2008, Mulrooney, 2007). Both of these studies focused on the lived experience of neurocognitive changes in women up to age 75 with early stage breast cancer who were of similar socioeconomic and educational background. A third qualitative study exclusively examines chemo brain in underserved African American breast cancer survivors (Rust and Davis 2013).

\section{Experiential Context}

In my clinical experience as an Advanced Practice Nurse (APN) in a private oncology setting, women with breast cancer who have had chemotherapy treatment complain of symptoms characteristic of chemo brain. In informal discussions with oncology nurses working in the private setting, the nurses reported that breast cancer patients receiving chemotherapy complain 
about being forgetful, having difficulty concentrating, and noticing a poor attention span, as evidenced by poor concentration while reading a book. Many patients use the term "chemo brain" to describe symptoms they are experiencing and are concerned whether these symptoms are likely to be long term consequences that may become permanent. Some patients are so worried about the potential long-term symptoms of chemo brain that they question the benefit of the chemotherapeutic prescription, despite the significantly improved cure rate.

In my clinical experience, I have observed that patients are frustrated and concerned about the loss of cognitive abilities that most of us take for granted. Healthcare professionals are just starting to recognize this symptom as a side effect of chemotherapy, but do not know how to evaluate it or treat it.

\section{Gaps in the Literature}

The concept of chemo brain was first documented by Silberfarb, Philbert and Levine (1980) as subtle changes in cognitive states. Chemo brain has not been well studied and has only recently gained the attention of healthcare providers and researchers. Although researchers may have studied the domains of cognitive function, different instruments were used to evaluate cognitive function in patients after receiving chemotherapy. Examples include the High Sensitivity Cognitive Screening (HSCS), The Profile of Moods States (POMS) (Brezden, Phillips, Abdolell, Brunston, \& Tannock, 2000), and the FACT-Cog, a specialized tool used to assess cognitive function in breast cancer patients (Janelsins, Heckler, Peppone, Kamen, Mustian, Mohile, Magnuson, Kleckner, Guido, Young, Conlin, Weiselberg, Mitchell, 
Ambrosone, Ahles, \& Morrow, 2017); however, no tool has been used consistently or effectively.

According to Hess and Insel (2007), more than 80 instruments have been used to assess various attributes of cognitive function in patients with cancer and no current standard exists for measurement or assessment of cognitive function in cancer patients. Von Ah, Jansen, and Allen (2014) reviewed 91 eligible articles regarding cognitive impairment between August 2010 and February 2014 to determine if evidence-based interventions existed for cancer and treatmentrelated cognitive impairment. They were able to break down interventions into four categories: likely to be effective, effectiveness not established, effectiveness unlikely, and not recommended for practice. Information about chemo brain and interventions used to treat it are still lacking. Nurses can offer support and assess for aspects of cognitive impairment but, knowledge about intervention and treatment will remain limited because of inadequate identification and inconsistent measures of the phenomenon of chemo brain.

Qualitative research that describes the lived experience of chemo brain in women with early stage breast cancer remains limited. Mulrooney (2007) studied the lived experience of selfreported cognitive impairment in women treated with chemotherapy for breast cancer. She interviewed 10 women between the ages of 18 and 75 who had received chemotherapy in the 1552 months prior to the interview. Similarly, Thielen (2008) explored the experience of neurocognitive changes experienced by women with breast cancer undergoing chemotherapy. The women in this study were currently being treated or had completed chemotherapy with 12 months of the study. The 13 participants were between 35 and 62 years old. Rust and Davis 
(2013) specifically studied chemo brain in underserved African American breast cancer survivors by conducting focus groups. Findings of Thielen's and Mulrooney's studies revealed that symptoms of chemo brain often started out as vague, but were cumulative, related to dose and worsened with each treatment and impacting all aspects of the lives of the women in these studies, while Rust and Davis found chemo brain to be variable among the women they studied. Mulrooney (2007) identified three dominant themes as a result of qualitative analysis: "I just don't feel like me," "trying my best to live with it" and "I am alive." Participants in this study stated that they had problems with memory, concentration, learning, language and multitasking and that chemo brain could occur at any time during treatment and had an impact on their ability to perform their usual activities. Coping mechanisms for these women were practical, but self-esteem was sometimes negatively affected. Some women reported more isolation from family and friends while others reported greater emotional support; however, all of the women felt that surviving was the most important thing of all.

Thielen (2008) identified eight similar themes following analysis which included: "Insidious recognition and delayed validation of cognitive changes," "Looking for answers in all the wrong places," "Attention: Can't keep my eye on the ball," "Underwhelming information for an overwhelming experience," "Work department: Hold please," "Missing Label: Caution: Woman on chemotherapy on board," "Coping: Not on the cancer journey alone" and "What the future holds." Women in this study found a decrease in cognitive function related to chemotherapy to be insidious and multi-factorial, yet were very resourceful in finding ways to cope and compensate with concentration and memory impairment. They were optimistic that 
changes in cognitive function were temporary and reversible and most of the women in this study had great support from family and friends.

Rust and Davis (2013) discussed four themes that overlapped with the themes of Thielen and Mulrooney. They included: the concept of chemo brain, variability among individuals, the stigma of chemo brain, and methods of coping. They found that individuals studied did not use health professionals as a resource for education and support during their experience of chemo brain. They concluded that nursing professionals are in the frontline of care and should be a resource for breast cancer survivors by providing information, education, and coping methods during the cancer journey. This, they hypothesized, would improve quality of life for breast cancer survivors.

Although these three studies examined cognitive changes in women with breast cancer, none of the studies exclusively addressed women 50 years of age and younger. Women in this age group often have different family, work, and social responsibilities that can be impacted by the effects of chemo brain (Von Ah, Haberman, Carpenter and Schneider, (2013)). Paraska and Bender (2003) state that cognitive dysfunction associated with adjuvant chemotherapy can affect the ability of women with breast cancer to maintain usual family, career, and community responsibilities. Women age 50 and under may have jobs that require higher cognitive functioning such as a business executive, university faculty or a lawyer. They may have multiple responsibilities that require them to multi-task in their daily lives at work as well as at home. They also have less diminished cognitive effects that could be accounted for by age-related changes that may occur in the absence of disease (Gazzaley, 2010), and therefore may have a 
different experience with chemo brain. The aim of this study is to gain a better understanding of chemo brain in women 50 years of age and under.

\section{Summary}

Chemo brain in women with early stage breast cancer is not widely understood.

Healthcare workers do not agree how to define it, let alone what to do for it. Women may be told that they may experience chemo brain during or after chemotherapy treatment, but are told very little about what it is or how to deal with it. Chemo brain has a major impact on the lives of the women who experience it. Family, social and work responsibilities are affected by chemo brain and will continue to impact lives until more information is learned about the experience of chemo brain for these women. Thus, understanding and acknowledging the existence of chemo brain is of extreme importance (Von Ah (2015). 


\section{Chapter III}

\section{Rationale for choosing method}

Qualitative research aims to ask to questions that allow data to reveal itself in its natural state (Munhall, 2007). Because there is a lack of understanding about the lived experience of chemo brain from the perspective of the women who experience it, a qualitative phenomenological approach was appropriate. According to Heidegger (1962), Husserl (1965), and Merleau-Ponty (1962) a phenomenological approach is appropriate when attempting to gain a deeper understanding of a real human experience, in this case, the lived experience of chemo brain.

\section{Background}

Qualitative research is strongly rooted in both the present and the past. Ancient philosophers were either scientists or physicians who were interested in how the world functioned, what was real, what was true, and what was of value (Munhall, 2007). Modern philosophers such as Heidegger, Husserl and Merleau-Ponty looked to explain and explore the world (Munhall, 2007). All philosophies, both ancient and modern, are based on assumptions about the world and comprise concepts that need to be explained, described and conceptualized, as well as analyzed to find the nature of being and the true meaning of the concept (Munhall, 2007). van Manen's (2002) methodology begins in the lifeworld and served to explore an everyday life understanding of the lived experience of chemo brain in women age 50 and under with early stage breast cancer. 
Translation of concepts and terms

Phenomenology- is the study of the life world-the world as we immediately experience it rather than as we conceptualize, categorize, or theorize about it. (van Manen, 1997).

Hermeneutics- to interpret or translate (Munhall, 2007).

Hermeneutic Phenomenology- is a qualitative research methodology that asks for meanings of a phenomenon with purpose of understanding human experience as it is lived (Crist \& Tanner, 2003).

Being- the nature or the meaning of a phenomenon (van Manen, 1990).

Bracketing- is a fundamental strategy in phenomenology which differentiates the chasm between phenomenology as a philosophy and as a research endeavor (Dowling, 2007).

Being in the world- the way in which human beings act and exist in the world. (van Manen, 1990).

Lifeworld-The world of lived experience as described by Husserl. "The world of immediate experience, the world as already being there "(van Manen, 1990, p. 180).

Essence- the nature of an experience is adequately described in language when the description reawakens or shows us the lived meaning or significance of the experience in a fuller or deeper manner (van Manen, 1997).

\section{General steps}

van Manen's phenomenological method was used to answer the question, "What is the lived experience of chemo brain in women 50 and under with early stage breast cancer?" This method used 6 general steps (Appendix A) to answer this question (van Manen, 1997). The first 
step is to turn to the nature of the lived experience. In this step the researcher orients to the phenomenon of interest, formulates a phenomenological question and explicates assumptions and preunderstandings.

The second step involves investigating the experience as it is lived rather than as conceptualized. In this step, the phenomenon is explored by using personal experience as a starting point, tracing the etymological sources, searching idiomatic phrases, obtaining experiential descriptions from participants, locating experiential descriptions in literature and art, and consulting phenomenological literature (van Manen, 1990).

The third step in van Manen's method is phenomenological reflection. In this step, thematic analysis is conducted by uncovering thematic aspects in lifeworld descriptions, isolating thematic statements, composing linguistic transformation and gleaning thematic descriptions from artistic sources by reflecting on them, recreating them, and transcending them (van Manen, 1990).

The fourth step is the phenomenological writing. In this step, the researcher focuses on the language, varying of examples and writing and rewriting. This is particularly important because in this step, the quality of writing makes the story become more compelling to both the researcher and to those that read it.

The fifth step involves manipulating a strong and oriented pedagogical relation to the phenomenon. In this step, rich, thick descriptions of the lived experience will help to give depth to the true meaning of the experience. 
The final step is to balance the research context by considering both the parts and the whole, and by taking into account all ethical considerations and knowing that the researcher may affect and be affected by the research (van Manen, 1990). 


\title{
Chapter IV
}

\section{Method Applied}

\begin{abstract}
Aim
The aim of the study is to describe the lived experience of chemo brain for women 50 years of age and younger with early stage breast cancer. This chapter describes specific data collection and data analysis that will be used to answer the research question.
\end{abstract}

\section{Participants}

A purposive sample of six women with early stage breast cancer who had just completed chemotherapy or had completed it in the within six months prior to starting the study and who had self-reported symptoms of the phenomenon of chemo brain, were interviewed in order to get a sense of what chemo brain meant to them and the impact that it had on their lives.

Flyers (Appendix B) were placed in private oncology practices in New York City and Westchester where participants were to be obtained; however, this recruitment strategy was not effective and participants were recruited through networking with nurses and friends through word of mouth. The women were asked to describe what it was like for them to experience chemo brain (Appendix H). In qualitative research, sample size is not determined by the need to ensure generalizability, but by data saturation (Higginbottom, 2004). In this study data saturation was reached with 6 participants. At that point, there was no new information provided.

Participants included women age 50 and under with early stage breast cancer (stages I \& II) who had the experience of chemo brain. The women ranged in age from 30-50, with one woman 29 about to turn 30, two others 38, the fourth 42 , the fifth 46 and the last woman, 50 . 
All of the women except for one (who had just completed chemotherapy) had completed chemotherapy within the previous 6 months and none except one required Herceptin therapy because of her HER2 positive hormone receptor status. All of the women were premenopausal prior to receiving chemotherapy and because of that; all were required to take Tamoxifen for 5 years after chemotherapy. All of the women were well educated and performed jobs that required high cognitive functioning. Two of the participants were teachers, but one was a stay at home mom since she was diagnosed while on maternity leave, 3 were nurses, but one of three was working in business instead of nursing and the sixth was retired from owning her own business. These women had multiple life responsibilities that required multi-tasking in their daily lives and were invited to participate because they had personal knowledge about the experience of chemo brain.

\begin{tabular}{|l|l|l|l|l|}
\hline Table 1. Participant & & & & \\
Profile. & & & & \\
Participant Name & Age & Ethnicity & $\begin{array}{l}\text { Educational } \\
\text { Level }\end{array}$ & Job \\
\hline Sherry & 42 & Jamaican & MSN & Nurse \\
\hline Julie & 38 & Caucasian & BSN & Nurse \\
\hline Cathy & 30 & Caucasian & M. Ed & Teacher \\
\hline Carol & 50 & Caucasian & BBM & Retired business owner \\
\hline Tina & 38 & Filipino & BA & Business executive \\
\hline Sheila & 47 & Caucasian & M. Ed & Teacher \\
\hline
\end{tabular}


Setting

Of the 11 interviews, five took place in the homes of the women, one was in a library conference room, one was in a Starbucks, one was in a hotel, two were at the participant's job site and one follow up interview was over the phone.

\section{Gaining Access and Establishing Rapport}

Because I was an experienced oncology nurse and a member of a professional organization, the Oncology Nursing Society (ONS), in both NYC and Westchester County, I planned to use my professional contacts to help me gain access. My plan was to speak at the monthly chapter meetings in Westchester and NYC after seeking permission from chapter presidents (Appendix F). I spoke at two meetings and followed up by attending monthly meetings in the hopes of identifying potential candidates, but this method did not yield any candidates. I continued to discuss my research with friends and work colleagues and participants were ultimately obtained by word of mouth through work colleagues and family friends. Being a member of ONS did not help to network with colleagues who could help identify potential participants as I thought it would.

Membership in a professional organization like ONS, as well as my in-depth oncology experience working with women with breast cancer, and the fact that I am a woman, did help to enhance my credibility as a researcher and helped to establish trust and rapport with participants.

In order to gain access to potential participants, the presidents of the local ONS chapters were contacted to ask for permission to speak at the monthly meetings (Appendix F). The study was described to nurses at the local chapters of the organizations to which I belonged, and I 
distributed a recruitment flyer (Appendix B) that contained information about the study and contact information for potential participants. Women who were interested in participating could contact me directly. Private oncology practices were also contacted by a written letter (Appendix E) where I asked potential participants to pass the study information along to fellow breast cancer patients in anticipation that this word of mouth communication would help to create a "snowball effect".

At the local chapter meetings of ONS, I presented the purpose of my research to oncology nurses who work in private practice settings in order to gain access to potential participants. I also asked oncology nurses to pass the word on to other colleagues in the private setting. I provided a flyer (Appendix B) outlining my proposed research to those women who might be interested in participating in this study. This flyer described the study and included the eligibility and contact information along with a statement informing participants that they would be asked questions about their experience with chemo brain after chemotherapy. The flyer stated that there was no monetary compensation for participating. Potential participants were provided with a letter of invitation (Appendix D). I explained to the nurses that when a woman would contact me, the proposed number of interview sessions, the amount of time for each interview, and information related to data collection and assurance of confidentiality would be provided.

I did not receive any participants via this formal method; however, I did speak to colleagues and friends about my proposed research and was able to get participants through word of mouth. All of the participants were gained through this method. 


\section{General Steps in Data Collection}

Basic demographic information (table I) was obtained from each of the participants during the taping of the first interview. These included: age, menopausal status, chemotherapy agents, number of cycles of chemotherapy, and hormonal treatments. This information helped to further describe particular attributes of the women who experienced chemo brain. Data collection was begun by interviewing each participant for one session with a follow up meeting to clarify information and further explore themes. This happened with all participants except for one who did not respond to follow up emails to schedule a second meeting. Interviews took 30 to 45 minutes and were kept flexible according to the needs of the participant. With their permission, each of interviews was audio taped. Field notes, memos, and thoughts and reflections, including reviews of particular statements made by the participants, were written after each interview was completed. Transcripts of the interview were typed up by the researcher. Transcripts were typed verbatim, within two weeks in order to obtain accurate data for analysis. After transcription of the interviews, the transcripts and the audiotapes of the interviews were reviewed simultaneously to ensure accuracy. Written field notes were used to describe the observations at all important phases of the interview including the initial contact, upon arrival, during the interview, when leaving the session, and at the termination of the final interview. Interviews were continued until data saturation was achieved and themes became redundant. 
Participants were asked to tell their story about their experience with chemo brain. They were also asked to give specific examples of their experience with chemo brain. At the end of the session, they were asked if they wanted to add anything to the interview.

Audiotapes were transcribed verbatim and reviewed by me while simultaneously being checked for accuracy. Once accuracy had been confirmed, initial data analysis was begun. This helped to identify additional questions for future interviews as well as identify any content that needed further clarification. At the end of each interview sessions, participants were thanked for their time and participation and were asked for their permission to contact them should further clarification be needed. At the end of each interview, participants were provided with a 25.00 Starbucks gift card as a token of appreciation for participating.

\section{Analysis}

Analysis of data was ongoing, and after the first interview, questions were identified for the next interview. I listened to the interviews and read and reread them as part of the process of developing codes, categories and themes. The categories were grouped into themes according to van Manen's method (Appendix A). By spending time reviewing the interviews and uncovering thematic aspects in the life world descriptions and gleaning the thematic descriptions that I was given by the participants, I was able to create themes to describe the life experience of chemo brain.

\section{Establishing and Maintaining Trustworthiness}

Trustworthiness was established and maintained by using the criteria of rigor in scientific inquiry as described by Lincoln and Guba (1985) as well as Sandelowski (1986). 
These criteria comprise four domains that include; credibility, transferability, auditability, and confirmability.

The principle of credibility is one of the most important elements of trustworthiness because it allowed me, the researcher to demonstrate that the findings are based in reality (Lincoln \& Guba, 1985). Qualitative studies are credible when they provide rich descriptions and interpretations of the phenomenon under study such that those who have had the experience would recognize the experience as their own or others can identify with the study just by reading it (Lincoln and Guba, 1985, Sandelowski, 1986). I was able to identify with the experience of chemo brain just as others reading the study could because of the rich descriptions and examples that the participants provided.

Three elements can enhance credibility in qualitative research. They are prolonged engagement, persistent observation, and triangulation of the data (Lincoln and Guba, 1985).

Prolonged engagement refers to the time the researcher spends establishing trust, understanding the culture and clarifying information (Lincoln and Guba, 1985). This allows the researcher and participant to build a relationship based on trust and understanding and will begin with the first interview. Credibility was enhanced by meeting each participant at their desired location. I went to two participant's homes for initial interviews as well as a follow up interviews. I scheduled a study room in the library for another participant in order to provide a quiet and private environment. I met another in a Starbucks near her job in downtown Manhattan for her interviews. The fifth participant asked me to meet her at her job for both of her interviews and the sixth set of interviews took place in a hotel. Each time I interviewed a 
participant, I would bring pastries and a Starbucks gift card as token of my appreciation for their participation in my study. By making myself available to each participant and meeting them where it was most convenient for them, I was able to easily gain access.

During the interviews, I observed and recorded observations in field notes. I often observed crying, anxiety, forgetting and scatterbrained behavior during these sessions. Continued observation along with writing field notes was an important part of the interview and data collection process. Reviewing field notes while transcribing the interviews allowed me to have a different perspective of the content that I may not have had without the field notes. They were an important part of the underlying and nonverbal content and reminded me of what I was thinking and feeling at the time.

Triangulation refers to the combination of two or more data sources that when put together, will form the essential data elements of qualitative research (Lincoln and Guba, 1985). Interview and observation served as two data sources that were used to verify the experiences and perspectives of the women, who shared their experiences of chemo brain with me, and helped me to confirm the meaning of the story. During the interviews, I observed behaviors such as crying, forgetting their train of thought, or showing a lack of focus, while in the midst of telling their stories. One of the women was crying because she forgot to pay a bill on time. Another women offered me coffee during the interview and asked me if I wanted sugar, but then forgot to bring it to the table when I said yes. She laughed and got up to get it but forgot it a second time. Another participant was 45 minutes late for the interview because she forgot to get gas in her car and could not find my phone number to tell me she would be late. When she did 
arrive, she came in flustered and spilled her coffee all over the library table. By observing the women when they told their story, the experience of chemo brain came alive with the words, gestures and actions used by the women, thus helping to verify the experience.

Transferability allows the reader to determine if the broad, rich descriptions described by the researcher are meaningful and able to be applied to their own experiences, and it is up to the reader to determine if the experience can be transferred to other situations (Lincoln and Guba, 1985, Sandelowski, 1986). Transferability refers to how well the descriptions fit to the experiences of others in similar situations. Consequently, the researcher must convey lived experiences in language that fully captures their essence. I focused on writing rich descriptions of the experience of chemo brain, using the women's own words.

Auditability is another important aspect of trustworthiness in qualitative research. Lincoln and Guba (1985) and Sandelowski (1986) believe that auditability is achieved when another researcher can follow the audit trail used by the investigator from its beginning to its end, follow the progression of events in the study, and has comprehension of the logic by the researcher. Trustworthiness is not a matter of claiming to be right about a phenomenon, but rather, it is a matter of having practiced good science. By making the path followed visible, for example, keeping careful documentation of all research transactions, it is auditable and therefore trustworthy (Sandelowski, 1993). The path of this qualitative research study has an auditable trail.

Finally the principle of confirmability was upheld. Confirmabilty is achieved when the findings of the study accurately describe the experience as well as the ideas of the participants 
rather than the subjective or objective stance of the researcher (Lincoln and Guba, 1985). The goal of this research was to accurately describe the lived experience of chemo brain in breast cancer without interjecting my beliefs about what the experience is. By having the participants confirm all conclusions and clarify ideas during the follow up interview, it ensured that the principle of confirmability was upheld and that the beliefs of the researcher were not implanted. By being aware of the researcher stance and when creditability or truth value, plus auditability, and transferability are established, then confirmability is also achieved (Lincoln and Guba, 1985; Sandelowski, 1986).

Trustworthiness was maintained throughout this research study by using the four domains of rigor, by saturating the data, and by conducting ongoing member checks that clarified and validated what was told about the experience of chemo brain. Additional attention was paid to decentering (Munhall, 2007), by being aware of thoughts and feelings about the experience of chemo brain, by really listening and by focusing on what the participants were telling me during each interview.

\section{Researcher Stance}

As a Registered Nurse with an advanced degree as a certified Nurse Practitioner (NP) as well as Advanced Oncology Certification (AOCN) who has worked in the private oncology setting for 16 years, I have treated many women with breast cancer. I know that with early detection, women in the early stages of breast cancer can be cured. I also know that younger women in general have different responsibilities than older women. Initially, I was not aware that chemo brain existed, but throughout the years, I have heard many women complain about 
vague symptoms of chemo brain; however, this is not always the case. I am not sure if they do not complain about it because the symptoms are so vague, because they feel that there is no treatment for it, or that they are afraid to bring it up. In my practice setting, we tried a variety of treatments, for example vitamin B12 injections, yet we could not even properly assess chemo brain.

\section{Protection of Human Subjects}

This research was approved by the SHU RB. The participants of this study were protected by adhering to the ethical principles and guidelines of good research as outlined in the Belmont report (NIH, 1979). Three fundamental ethical principles exist that protect human subjects. These are autonomy and respect for persons, beneficence, and justice.

During the informed consent process and throughout the study, the principle of respect for persons and autonomy were sustained. Participants were provided with a copy of the consent form (Appendix C) and were reminded that their participation was voluntary and that their consent could be withdrawn at any time during the study without consequence. Participants were provided with all the necessary information needed for informed consent including: the aim of the study, privacy/confidentiality procedures, risks/benefits of participating in the study and my contact information for any questions or concerns throughout the study.

Participants in the study were assured that all of the information obtained throughout the study would be kept confidential. All interview tapes and transcripts were secured in a locked filing cabinet when not in use. Informed consents were kept separate from transcripts in a second locked file cabinet. In order for participants to remain anonymous, each was be given a 
number so that their information would remain confidential throughout the study. All tapes and field notes were kept for a period of at least three years as per the Institutional Review Board (IRB) application at Seton Hall University.

The principle of beneficence guided me throughout the research. Women who agreed to participate in the study gained personal satisfaction by telling their experience of this little known phenomenon. They were listened to and allowed to describe their experience of living with chemo brain. They were also provided with a list of support groups (Appendix G) in the event that discussing their personal experiences with chemo brain distressed them in any way. The principle of justice ensures the fair distribution of benefits and costs to potential research participants (NIH, 1979). Participation in the study was voluntary and all participants were treated equally, fairly, and ethically. Information gained from this research can only add to the limited body of knowledge regarding chemo brain in breast cancer and will benefit women with chemo brain symptoms as a result of chemotherapy for breast cancer in the future. 


\section{CHAPTER V}

\section{Participant Profiles}

\section{Carol}

Carol was diagnosed with breast cancer when she was 49. She had previously been diagnosed with Hodgkin's disease when she was 25 years old and was treated with radiation therapy to her chest for about 6 weeks but did not require chemotherapy at that time. She believed that she got breast cancer as a result of radiation to her chest. Her treatment protocol for breast cancer was not easily determined because of her earlier radiation and her options were limited because of the past radiation. After many discussions with her team, it was decided that Carol would receive surgery, chemotherapy with cytotoxic drugs, and hormonal therapy. She had a double mastectomy with reconstruction and did not require further radiation. She was anxious to get treatment over with and move on with her life.

Carol is a wife and mother of 12 year old fraternal twins and life is busy. She was from Jewish descent. She has an upper middle class background and lived in NYC until she had her twins and then moved to Westchester with her husband and children. She has one brother and her father was still living. She is very close to them. Her father has a history of Alzheimer's disease for the previous 10 years and she was always looking for ways to improve his memory; techniques that she would later try to improve her own memory. She has a master's degree in guidance counseling and owned and ran a multinational clothing business for 10 years. She is organized, hardworking, and great at multi-tasking and did not need to rely on others for help prior to receiving chemotherapy for breast cancer. 
Carol indicated that prior to receiving chemotherapy, she had a photographic memory and prided herself with never needing to write anything down. In fact, she was able to run her own business of 682 employees without using technology to assist her. She could even remember phone numbers without looking them up. Chemo brain was devastating for Carol. It affected most aspects of her life including being organized, multitasking, remembering details and phone numbers, and getting to places on time. Simple tasks, like grocery shopping, remembering main events, even being on time to commitments became daily struggles and greatly affected her social and emotional well-being. Although Carol needed to rely on her friends, husband and children to assist her with daily routines, she did not give up trying to improve the quality of her life. Carol was interviewed 6 weeks after completing chemotherapy.

\section{Cathy}

Cathy was diagnosed with breast cancer when she was 29. She had recently given birth to her son when she found a lump. Her gynecologist thought it was a blocked duct because she was breastfeeding but upon further workup was found to be breast cancer. Cathy, as were her doctors, was surprised to hear that she had breast cancer. She was young and had no family history of breast cancer. Cathy's treatment consisted of surgery, chemotherapy with cytotoxic drugs and hormonal therapy. She received a mastectomy with reconstruction and did not require radiation.

Cathy is a wife, mother of 2 children, and a teacher. She has a master's degree in special education and had been teaching for three years prior to her diagnosis. She has 3 sisters and her parents all living close to her. She is of Irish descent. She lives in a middle class neighborhood in 
a suburban area in Westchester County and was home on maternity leave when she received her diagnosis. She considered herself to be hardworking, organized, charitable, great at multi-tasking and caring prior to chemotherapy.

Before getting a diagnosis of breast cancer and receiving treatment, Cathy was the one that everyone relied on for help. She is the oldest in her family and was used to being there for others. She worked with small children and was able to multi-task. She was able to accomplish multiple things at the same time both in and out of school.

Chemo brain was difficult for Cathy. Not only did she have hormonal fluctuations as a result of recently giving birth, but she also had hormonal fluctuations as a result of chemotherapy and hormonal treatment which further compounded cognitive dysfunction. She felt fatigued and had difficultly remembering to do things. Cathy would walk into a room to get something and forget why she was there. She relied on her husband, mother, sisters, friends and even her little 7 year old daughter Emily to remind her to take care of everyday tasks. She also relied on her vast support system to help with the children, preparing meals and getting her to chemotherapy appointments. Cathy was extremely frustrated by the havoc that chemo brain had on her life. Cathy was interviewed 1 year after completing chemotherapy.

\section{Julie}

Julie was diagnosed with breast cancer at age 38 . Her diagnosis came 2 months prior to her getting married. She had no family history of breast cancer but decided to have genetic testing anyway. Thankfully, her results were negative for the BRCA gene. Before starting chemotherapy she did fertility preservation, and went on her honeymoon. Upon return from her 
honeymoon she started chemotherapy. Her treatment consisted of surgery with a lumpectomy, radiation, chemotherapy with cytotoxic drugs and hormonal therapy.

Julie is the youngest of 3 daughters. She came from an upper middle class Italian background and lived on Staten Island. She is very close to her family and they all live nearby. Julie worked as a medical biller prior to going to nursing school at age 28 . Her first nursing job was in a hospital setting before working as a corporate nurse for 5 years. She then moved back to the inpatient setting. She bought a house that needed renovations and was working hard to attain her goals of completing the renovations on her house and becoming a mother. She was organized, goal oriented, and had a great memory before chemotherapy.

After receiving the diagnosis of cancer she said she felt like a "failure" and felt as though her body wasn't strong enough to fight off cancer. Not only did she have feelings of inadequacy but she also had to deal with the experience of chemo brain.

Chemo brain changed Julie's life. She had many changes taking place at the same time. Her in vitro fertilization treatments did not work. She started a new job and was having difficulty keeping up with life's demands. Julie was overwhelmed. She was always good at remembering tasks and details, names and faces, and staying organized. When she completed chemotherapy she initially thought when asked about chemo brain that she didn't have it but months after treatment she realized that she did. That was when all the difficulties occurred. She had difficulty with memory and concentration and quickly noticed that she did not feel as sharp as she did before and needed to be assisted by family, friends, coworkers, and technology. Without this assistance Julie said she would not have been able to go along with daily activities. She now 
had to learn new strategies to help her cope with these cognitive changes without constantly relying on her family. Julie wanted to have a baby and become debt free but the side effects of chemotherapy made it hard for her to achieve her goals. Julie was interviewed 1 year after completing chemotherapy.

\section{Sheila}

Sheila was diagnosed with breast cancer at 46 . Breast cancer was diagnosed after a routine mammogram. She underwent a mastectomy with reconstruction after several cycles of chemotherapy with cytotoxic drugs, but experienced many barriers along the ways. She developed an infection at the breast reconstruction site and was hospitalized and had to have a central catheter placed in her arm in order to continue antibiotics at home. She also had a strong family history of breast cancer and had to have genetic testing done to rule out hereditary breast cancer. She did not test positive for the BRCA gene but 2 of her sisters did. Because of the strong family history, the doctors recommended that Sheila also have a full hysterectomy to minimize estrogen factors. She was placed on hormonal therapy prior to her hysterectomy but did not require radiation.

Sheila is a wife and mother of 2 teenage boys and responsible for the family dog. She is Irish American, middle class and is a special education teacher in the local community. She has a master's degree in special education. She is very close to her sisters who live within a 30 minute driving distance. Both of her parents are deceased; her mom from breast cancer.

Sheila indicated that before starting chemotherapy, she was organized because she had to be prepared for her students. Between work, home life and family, Sheila was kept busy but she 
did not have any problems keeping up with her daily activities until the effects of chemotherapy began to take its toll. Because of all the side effects and complications that Sheila was experiencing, she had to miss much of the school year. Her life was put on hold. Sheila did not know what chemo brain was per se, but knew that she was experiencing cognitive decline and was unable to keep up with the demands of her life. She said that lost over a year of her life because she could not be fully present. She had to rely on family, friends, and coworkers to help her cope with everyday life. Sheila was interviewed one year after completing chemotherapy.

\section{Sherry}

Sherry was diagnosed with early stage breast cancer at age 42 . She could not believe that she could receive this diagnosis. She started getting mammograms in her early 30 's because she had cystic breasts and was vigilant about monthly self-breast and yearly professional breast exam. Her breast cancer was caught early and she thought that all she had to do was have a lumpectomy and to check her lymph nodes, however, diagnostic testing and prognostic factors indicated that she did indeed need chemotherapy. She began a cytotoxic regimen and then had radiation therapy and hormonal therapy.

Sherry was a born in Jamaica and migrated to the United States when she was 10 and her culture and family are very important to her. She loved her life. She was newly married for a year prior to her diagnosis and has 2 teenage stepsons that she adored. She also had a new dog that quickly became part of her family. She has a deeply religious background and trusts God in all matters. She is a nurse for over 20 years who started working as an Oncology nurse administering chemotherapy in the hospital setting then worked with the NCI counseling women 
with breast cancer and finally earned an advanced degree in psychiatric nursing and she knew about cancer. At the time of diagnosis, she was working in the field of nursing informatics and was very knowledgeable in research and technology. Sherry was very intelligent and considered herself a nerd. She always went the extra mile and provided more information than was required. She was well organized, well-spoken, a great multi-tasker and known for her writing and communication skills. She said:

Ok, I'm a nerd. You know, I'm the one with 3.8 GPA throughout college and schools and it's been even 4 at times and I gotta get the A you know and the teacher asks you for like a 10 page paper and mine was 25 pages. I'm the girl where when I sat in my college classroom and the teacher would go through the criteria for the paper they'd look at you and say only 10 pages. You know they'd look at you and say like ok Sherry, yes you. So, I'm the one who would stick a note with my term paper and tell the teacher that the first 10 pages is what you wanted ; the other 10 pages is what I thought you needed, you know (laughing). And I said just go ahead and just grade the first 10, but I just want you to read the other you know. So that's me, you know.

Sherry was living a dream and then was diagnosed with breast cancer and her world turned upside-down. She experienced many side effects as a result of her chemotherapy including nausea and vomiting, fatigue, hot flashes and worst of all, chemo brain. She had heard about it but did not believe that she would experience it. Sherry was devastated by her experience with chemo brain. Communication skills and writing came naturally to her. She loved to journal but after chemotherapy, she had great difficulty trying to express herself. Her 
memory was also greatly affected. She could no longer remember things that were important to her like birthdays and anniversaries and even appointments. Chemo brain changed her life. She was a woman in charge, but now had to take a backseat and let family, friends and coworkers assist her. Despite her diagnosis, Sherry believed that her cancer journey was to serve a purpose and she trusted that all would turn out well. Sherry was interviewed five weeks after completing her last chemotherapy treatment.

\section{Tina}

Tina was diagnosed with breast cancer at 38 . She always checked her breasts on a monthly basis. She found a lump and was concerned. She had gone to nursing school and had an LPN license so she knew it was not good when she found the lump. She did not have a regular gynecologist and had difficulty getting an appointment. She called several offices but no one would give her an appointment to be seen for at least a month. She finally found someone who could fit her in and the process began. She had a biopsy of the lump with a sentinel node biopsy and breast cancer was revealed. Tina immediately started chemotherapy with cytotoxic drugs and after several treatments, underwent a double mastectomy without reconstruction. After surgery, she completed chemotherapy and began treatment with monoclonal antibodies and hormonal treatment.

Tina is a middle class lesbian woman from the Philippines who lives in NYC since she came to the country almost 20 years ago. At the time of the first interview, Tina was in the process of bringing her fiancé and her children over from the Philippines so that they could marry and she could adopt the 3 teenage children and they could begin their life together. She 
has no other family in the United States and is anxious for her new family to come. Tina works in business but also went to nursing school to become an LPN. She worked hard and was great at doing what she had to do. She could remember everything she needed to do without writing it down. She was proud that she could do her job so well without relying on technology before she received chemotherapy.

Prior to beginning chemotherapy, Tina was well organized and could multi-task without difficulty. She did not need to rely on others to do her work. She did her job well and enjoyed her life until she started to experience chemo brain. Chemo brain had a major impact on Tina's life. She started to notice that she had difficulty finding words and remembering things on her to do list; things that she was known to do well. She did not want to admit that she experiencing chemo brain and tried to exercise her mind by remembering rather than using technology. She would use her outlook account as her backup to her memory and found that she often left something out. Her coworkers were very helpful in reminding her to get to appointments and when her family came from the Philippines they too helped to remind her about daily things. Although she was grateful for the help and support, Tina felt that she lost her independence. Tina wanted her life to return to what it was before and show her new family that she was still independent and able to take care of them. Tina had completed chemotherapy 3 months prior to being interviewed but was still being treated with Pertuzumab and Trastuzumab monoclonal antibody infusions every 3 weeks. 


\section{CHAPTER VI}

\section{RESEARCH FINDINGS}

Chemo brain refers to cognitive changes in brain function as a result of chemotherapy (Staat \& Segatore, 2005). Cognitive dysfunction as a result of chemotherapy could manifest in many ways, such as, an inability to concentrate, remember details, and complete familiar tasks as quickly as done prior to treatment (Staat \& Segatore, 2005; Gazzaley, 2010; Jenkins et al., 2006). The purpose of this study was to answer the research question "what is the lived experience of chemo brain for women 50 years of age and younger with early stage breast cancer?" and to describe their experiences. All 6 women had a unique story to tell.

Based on the analysis of data gathered through individual interviews, five main themes emerged: (1) struggles with day to day life, (2) fatigue, (3) emotions related to diagnosis and treatment, (4) coping with cancer and support during cancer, and (5) feeling grateful for surviving cancer.

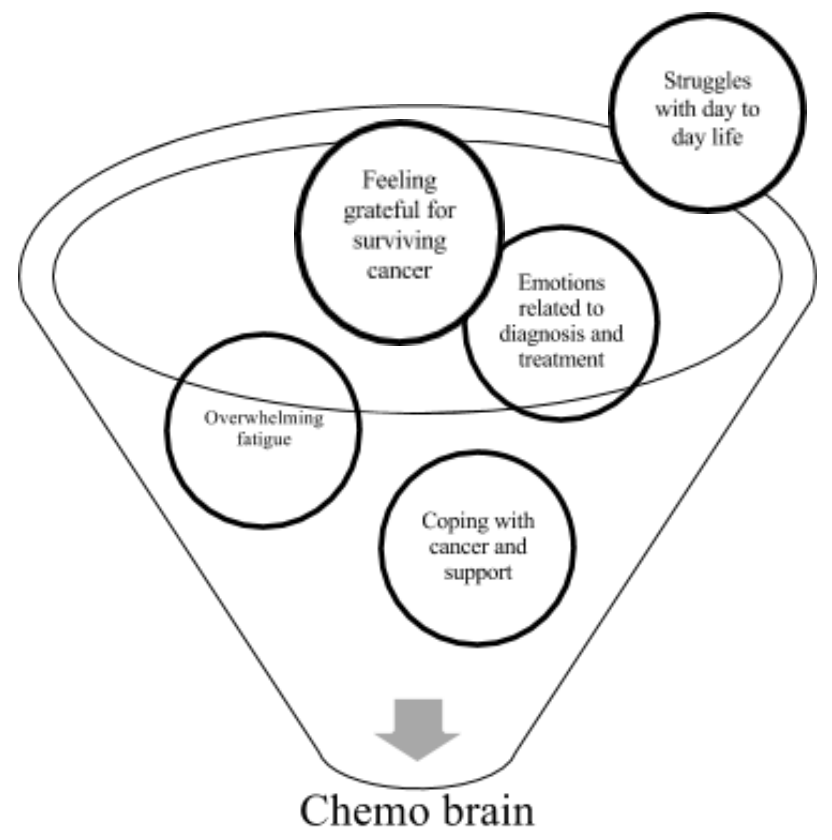

Figure 1. Connection between the Emerged Themes and Chemo Brain 
In addition, four main sub-themes became apparent in relation to the first main theme about struggles with day to day life. These sub-themes include: (a) memory loss, (b) difficulty with concentration, (c) inability to communicate using writing skills/disorganization of thoughts and words, and (d) difficulty keeping track of and managing time.

\section{Struggles with Day to Day Life}

In this study, all six participants describe cognitive dysfunction and they described four main daily struggles related to it, including: (1) memory loss, (2) difficulty with concentration, (3) inability to communicate using writing skills/ disorganization of thoughts and words, and (4) difficulty keeping track of and managing of time. All the participants mentioned these four areas as major challenges in their daily routines and activities, interfering greatly with all aspects of their daily life. A participant commented: “You're very forgetful. I wouldn’t remember. I also felt like I couldn't concentrate." In relation to this aspect, another participant explained: "I lack concentration that I used to have. I don't focus as clearly. That's all happened after the chemo".

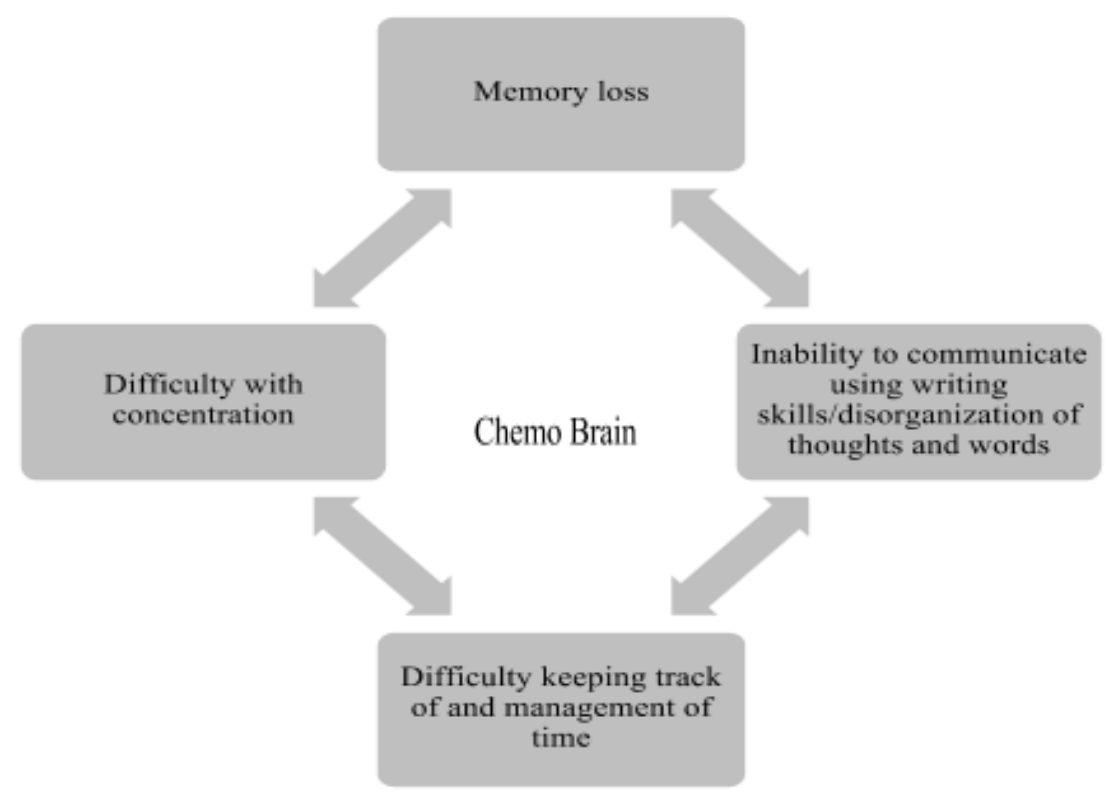

Figure 2. Sub-themes Related to Struggles with Day to Day Life 


\section{Memory loss.}

In regards to memory loss, Julie explained, “I found that I couldn't remember things. I was really good at remembering names and faces and everything. I find that that's a lot more difficult now. That's all happened after the chemo." While Cathy had difficulty remembering simple tasks, like laundry. She said: "It's really weird. Like I go upstairs to get the laundry and I'll come down and I'll get sidetracked with other things and I'll come down without it." Sheila also had issues with her memory, and commented: "at work I wrote a lot of post-it notes, even everything I was going to do that day teaching in class because I would get distracted and forget. I would just go off on a tangent on something else.” These are three examples of how the memory aspect of cognitive dysfunction manifested, and how much of an impact it had on participants' daily lives.

Memory loss in most participants was related to the side effects of receiving cytotoxic drugs and hormonal treatment. The challenge of enduring memory loss affected them daily. It had impacted them personally, their family life and their work life because they could not remember to do things that they did without question before cancer and chemotherapy. Most of them got through the day but all of their stress and extra efforts made to compensate for their imposed memory loss often left them feeling confused and tired. Julie reflected: "I can't think right now. I'm tired. My brain is not functioning a hundred percent." In addition, Sherry commented, "I don't by any means have the energy that I did before and it takes me a lot longer to do stuff and that's been hard." These examples indicate the extra energy necessary that participants had to expend in relation to memorization. 
All participants were disturbed about the way memory loss impacted their lives and the impact it had on how they felt about themselves. Sherry was upset that her memory was failing her. She shared her feelings when she said: “The fact that I couldn't remember really special things really bothered me". She commented that she previously remembered sending cards for special occasions like birthdays and retirements and would remember to text a friend to wish her well when she had a job interview, but after chemotherapy she no longer could. This caused her great distress.

\section{Difficulty with concentration.}

Most participants in this study indicated certain difficulties with concentration. This difficulty was another main area related to cognition and a decline of functionality that most participants agreed affected them and their relationship with others. Participants described having to spend more time and needing to reread materials because they could not grasp ideas the first time. Julie explained "I had a really difficult time just concentrating. I was in school for my Bachelor's degree so I just stopped going." Sheila added, “I couldn't concentrate. I couldn't remember. I couldn't read a book." Most participants also had difficulty reading books and paying attention at work, for example in meetings and conference calls. Sherry explained:

So I had to pull away from it and then come back to it, to say okay, 'now what is it saying?' So the concentration is still bad and ...it doesn't come as quickly as before. So I

know that and because of it, I have to reread stuff more to just make sure it sounds okay. Before I didn't really have to put that much effort into it. 
Another participant, Carol, felt that she had to work much harder just to keep up with daily demands and could only focus on one thing at a time while in the past, she could easily multitask. Carol said: "I found that also I lack concentration that I used to have. I don't focus as clearly. She explained, "I have to de-compartmentalize everything. Like that goes there. Your mind is like almost working twice as hard now". These are just a few illustrations of the effects that chemo brain has on concentration which impacts work life and everyday life. The participants described having to work much harder after having the experience of chemo brain. They had to spend more time completing tasks that they had no trouble completing prior to receiving chemotherapy.

\section{Keeping track of and management of time.}

Time management was an area of concern for all women in this study. They all related challenges on keeping track of time due to chemo brain. Carol commented:

I cannot make it anywhere on time. I can't get myself, even knowing, even trying to get myself out the door like say okay when I write the time down on my calendar say it's at 11 and I write down the appointment, I am still late.

As Carol, Sherry also had similar experiences with time management. She was always the first person on the line waiting for the rest of her team for conference calls until she had chemo brain. She said:

The job was calling and I thought oh, someone from work is trying to check in and they say, "Sherry, are you going to join the call because we started about 10 minutes ago and we didn't want to call and bother you. 
All six participants in this study expressed distress over their lack of ability to complete tasks in a sufficient amount of time. This situation made them feel insufficient, and simple tasks and regular activities took much longer and required greater efforts to complete. In Sheila's words: "At work I wrote everything I was going to do in because I would get distracted and forget. I would go off on a tangent on something else."

These feelings were supported by other participants, such as Cathy and Sherry. Sherry explained:

Usually I am in front of 2 computer monitors. I have the domain which is the training part that we are building of the electronic medical record and then on another computer monitor, I have a spread sheet. So, what usually happens in my work, I go from the domain to the spread sheet back and forth, back and forth. So, I am checking what's in the domain and making sure that it's in the spread sheet or vice versa. In the spread sheet is the data elements. Because the spread sheets would start to get blurry and confusing and I am like is this line 110 or is it line 120 . Because I really had to pay attention to rows and columns and I couldn't do that. So that's how I ended up using a lot more medical leave than I originally thought. You know I couldn't really focus.

Financial demands were an example of a stressful area that was indicated by several of the participants. Sherry got behind on paying her bills because she no longer managed time demands well and could no longer keep track of when bills were due. She explained: 
I got behind on bills so I ended up during chemo paying a lot of late fees because I just wasn't as organized so the whole concept of chemo brain interferes with your ability to really organize your life not just the medical part but your home life you know um your financial life has to do with you pay your bills on time.

Sherry became very emotional about this issue and cried about this during the interview. She was always able to keep track of things and keep up with home and work demands until she had the experience of chemo brain and could no longer remember appointments or pay bills on time. Like Sherry, Sheila also complained about her lack of memory and organizational skills caused by chemotherapy. She would forget things like paying bills on time and booking appointments on a daily basis, she said:

I'll say to myself, Oh, I really need to book that doctor's appointment, and then 5 hours will go by, and then I'll say, Oh my God. I never booked that doctor's appointment. Things just completely slip your mind, but I don't know if that's part of getting older or if it's from the chemo.

Overall, participants in this study felt that keeping track of time and time management was difficult as a result of experiencing chemo brain and commented on this many times throughout the interview. This inability to focus on particular tasks and plan ahead made most participants feel unable to perform in their jobs and daily activities as they did prior to chemotherapy.

Inability to communicate using writing skills/disorganization of thoughts and words.

Research findings in this study indicate that cognitive skills, such as writing and the organization of thoughts and words were compromised. Sherry explained: 
I knew what I wanted to write. I wanted to write about what I was going through that day and some of the conversations I was having with God. I couldn't get the words together you know. And that was really hard because I don't usually have a problem with words. So, focus and word construction and sentence construction- I just couldn't put it together you know, and it was frustrating.

To this, Tina added: "One thing I also noticed about the chemo is words. Words that escape me. Even simple words." Difficulty finding words to describe something was evident throughout the interviews, for example when Tina wanted to borrow my pen but could not remember what it was called. She asked for "the thing you write with" instead. Sherry and Tina both found that this had an effect on the ability to do their jobs. This was difficult for both Sherry and Tina as it was for all of the participants of this study. These women were all hard working individuals whose jobs required attention to detail as well as impeccable verbal and written communication skills.

To summarize, research findings in this study indicate that all six participants were affected by the experience of chemo brain and this took a toll on their ability to fully participate in all aspects of their lives. The six participating women in this study were unable to maintain their usual daily activities while having the experience of chemo brain that began shortly after starting chemotherapy and continued through the interview process. All of them explained that it took them longer to do their routine activities and errands, such as housework and laundry, as well as going to the grocery store after receiving chemotherapy. They found the need to pace 
themselves and take breaks while doing them because of the debility they felt both mentally and physically.

Chemo brain had devastating effects on the lives of the women in this study. Minor tasks became something that had to be planned for in advance with reinforcement. They could no longer take things for granted. Carol, as all participants, was frustrated by her lack of organization. She described her trips to the grocery store as a clear example of how disorganized she felt and described herself as having a scattered mind. She explained:

The grocery store is all of eight minutes from my house, so even if it is a bad day, the whole thing should have taken me a half hour. Two and a half hours it took me.... Because I left my house five times because I forgot my wallet, my bag, my keys, and then finally the list.

Thus, chemo brain prevented participants from working to full capacity and participating in usual family activities. The women in the study experienced cognitive dysfunction that had a profound impact on essential aspects of their lives. They dealt with daily disruptions of even the simplest activity that most people would take for granted.

\section{Overwhelming Fatigue}

The majority of the women felt fatigued during the treatment process and had a difficult time in completing the demands of day to day life in the ways they had prior to treatment. They explained it as being different from feeling over tired. In fact, they felt overwhelmed by it and were unable to perform their usual activities because of it. I was able to understand how much fatigue impacted each of their lives by hearing their stories. Sherry prided herself on being able 
to multitask and get so much done before chemotherapy, but after receiving treatment for breast cancer, she said: "I don't by any means have the energy I did before. I was like super energizer bunny". Cathy too felt like she could not participate in her family life during chemotherapy and for some time afterwards. She explained:" I remember it took a while for me to actually get my energy back. There are even still some days when I'm just like, why am I so tired?" and added "I wasn't able to like clean or do laundry or pick up the kids or drive". Carol added," there are days I probably didn't want to get out of bed. I got out of bed, but probably could have stayed in bed".

Tina was athletic and an avid volleyball player prior to starting chemotherapy, but after starting treatment she said that she gained weight and lost energy and was not able to play while on treatment. Julie stopped going to school while on chemotherapy because she did not have the energy to get her work done and Sheila was unable to work at all because of the effects of chemotherapy that included fatigue. Thus, fatigue had a major impact on life during and after chemotherapy.

\section{Emotions related to Diagnosis and Treatment}

All participants in this study expressed strong feelings and emotions, like fear, anxiety, and anger in relation to their experience with the diagnosis of breast cancer, treatment, and side effects of chemotherapy like chemo brain. Not surprisingly, because of the multitude of cognitive changes and emotional distress reported in dealing with a cancer diagnosis, all participating women had strong emotions about their cancer experience. Some of the participants even expressed a sense of failure for succumbing to cancer. Julie expressed, "after 
receiving the diagnosis of cancer I felt like a "failure" and felt as though my body wasn't strong enough to fight off cancer." Also, Sheila commented: "I tried not to let myself go down there, to the dark, sad things because I knew it wasn't going to do me any good. I'm kind of good at pushing that down."

A range of feelings and emotions were expressed by all six participants from the time of diagnosis through survivorship. Some of the main feelings expressed included being afraid, nervous, depressed, indecisive, anxious, frustrated, and stressed. Women in this study wanted to talk about their experiences and share them with others in order to help themselves cope with the experience of having cancer, as well as to help others understand what this experience meant to them. Similar opinions regarding the emotional aspects of chemo brain were expressed by Cathy, Carol, and Sheila. For example, Cathy was filled with emotion about her experience before and after getting diagnosed and starting treatment, and she explained:

I would get myself so worked up and convince myself that something is wrong and have to tell myself that everything will be fine. ...Especially with no family history. It was just so sudden, you were so young...there were so many scenarios here. ...And once it happens to you it is always in the back of your mind. Is it going to happen again? Because you know you never expected it to happen so it's always in the back of your mind.

In her own words, Cathy was trying to voice her concern for the future, and was very adept in expressing herself. Like Cathy, most participants worried about their future, as well as the treatment itself, but despite the fear of the unknown, the majority of the women also felt thankful 
that the cancer was found and that they were being treated and would be cured. They were also thankful to have the wonderful support systems that helped to get them through treatment, such as family, friends, and coworkers. Regarding her coworkers, Tina said: “They help me a lot. They make sure I get to my appointments on time. "Oh Tina, it's 02:00, you have an appointment at 03:00; you've got to go." To this, Julie added: "My husband was super supportive. Really was. I would say my other family members were but my husband was a dream, was an angel." Sherry, for example found it difficult to give up control, but realized how important it was to her journey that she relinquish some of her responsibilities. She explained: I also had my husband more involved in helping me remember stuff you know cuz he would go with me to a lot of appointments um, but the times I was well, I would go to the appointments by myself. So I needed...I think it's important to let your loved one know kinda what you're going through, that you are having trouble and ask for help. And for me, I think a part of this journey was that too. That was not easy for me.

In regards to the diagnosis and prognosis, all participants accepted their diagnosis and believed that they were cured and despite having a cancer diagnosis and knowing that the cancer could return, each one found a positive outcome from having gone through the experience. This helped them to set priorities in life and understand how fragile life can be. Although Cathy had a difficult time with side effects, she felt a sense of security while on chemotherapy and became nervous when she completed chemotherapy. She reflected:

It was interesting um during chemo I would see Dr. D every two weeks...you know when somebody is watching you, monitoring you and then when I stopped seeing her... I 
would go to her every four months, then every six months it made me so nervous because I am not being monitored the way I was you know what I mean? ... What's happening over those six months that I am not having bloods drawn...it was just so....I mean I think it will always be at the back of my mind, you know to have that thought of oh what if it comes back. I know I will never not feel that way, but I mean at the beginning it was there. You know when you finish your treatment it's like you have to get back to a normal life. You were so used to going to the doctor and having her check me...

Cathy was able to articulate both negative as well as positive experiences about her cancer journey. Despite the difficulties, participants connected with their emotions in the past as well as the present. They were fearful and angry about their diagnosis and concerned for their future, but eventually came to believe that they would be cured of cancer. They were able to describe a transformation in their worldview due to their experience with cancer. Still, some of the participants expressed anger about having the experience of chemo brain during the cancer experience. Julie indicated manifestations of denial and fear when she first began to experience cognitive changes and explained that she did not want to admit that she was having the experience of chemo brain even though she knew in her heart that it was chemo brain. She was already dealing with so much in her own life that the chemo brain was more than she could deal with. She reflected, "I was in denial that that would be anything. I realize now that I think I definitely had chemo brain". She said that she knew that she was experiencing chemo brain right away but was angry about it. Thus, the cancer/chemotherapy experience triggered a variety of emotions from denial to acceptance, often happening concurrently, in the women in this study. 
Coping and Support During Cancer

Coping with chemo brain was both physical, as well as emotional for the six women in this study. By using physical compensatory mechanisms like, electronic devices and sticky notes, calendars, and by being supported by friend and loved ones, all participants indicated that they were able to find ways to cope with challenges and setbacks due to chemo brain.

All participants found effective ways to compensate for their chemo brain. They used technology, as well as more conventional ways, including writing notes and setting alarms to help them navigate through their daily routines, responsibilities, and unanticipated events. All of them mentioned the use of smartphones with alarms and reminders, calendars, sticky notes, and lists as effective ways to aid them with daily life activities. Julie explained: "I make lists and carry them in my pocket so I can add to them." Also, Sheila said: "I write everything down so I don't go off on a tangent."

Each participating woman used a combination of techniques to cope with the cognitive deficits they were experiencing. As Sherry described: "my phone has an alarm thing in it and it can alarm not just on time but events. So if I put an event in my phone; it's a smart phone. So my phone alerts me." All of them questioned how they would have coped if they had had the experience of chemo brain before technology existed. Carol commented: "I put all of the phone numbers in the phone now, but I used to remember them all before chemo brain.”

Use of technology was an important coping resource for all six participants. Julie and Cathy used their smartphones as part of their daily routines to remember important information like appointments and taking their medications. Julie said, "I keep notes; I keep my cell phone, a 
lot of reminders in my cell phone. I set the alarm clock so I know that it's going to happen.” While Cathy used the alarm to remember to take her Tamoxifen saying, "so I'd set my alarm every day at the same time". Sherry too used her smartphone to remind herself to do important tasks. She explained: "yeah, I got a new phone that's helpful because I use a daily task reminder and it alerts me with different tasks." She found this to be very helpful to keep her on track.

Despite having an abundance of computer assisted technologies available to aid with cognitive decline, some participants chose to use written notes and to exercise the brain to prevent further decline, as well as to continue their effort to function as well as they did before the chemotherapy. For example, Sheila explained:

at work I wrote a lot of post-it notes, even everything I was going to do that day teaching in class because I would just get distracted and forget. I would just go off on a tangent on something else.

Tina tried to make mental notes, but she also used her outlook calendar as a backup. She wanted to maintain as much of her brain power as possible without relying on technological support, and believed that using her brain would help to strengthen her memory, but used her Outlook calendar as a backup to assure that she had not forgotten anything. Tina commented: I'll make a mental note of it. And the first thing I do when I come in the morning is just see what it is, how much I remember. Instead of me making a note, I just look on my email, on Outlook. I just mark everything that I didn't get to process in red.

Compensating for chemo brain was important to all women who participated in this study. They wanted to continue on with normal life and the responsibilities associated with it as 
they did prior to chemotherapy and were willing to use any means possible whether post it notes, smartphones, or the help of others in order to function.

In relation to feeling supported during the cancer experience, all participating women expressed their gratitude towards family, friends, and sometimes co-workers for their support and understanding throughout their cancer diagnosis and treatment. They thought that they would not have made it through the experience of cancer, chemotherapy, and chemo brain without a strong support system. Julie explained that her husband and family were really there for her throughout treatment, and commented: "yeah, my husband was super supportive. Really was. I would say my other family members were, but my husband was a dream, was an angel." Sherry also had a strong network available to support her in the process and indicated: "you have resources and you like use them, especially a support network. You know, let people know on the days I'm not having a good day."

In regards to family support during cancer treatment, Cathy too expressed thankfulness of her family and friends and even had the assistance of her young daughter, saying "sometimes even Emily (young daughter) helps remind me of things". She also relied on her sister for activities of daily living. She explained: “I couldn’t even, like literally, my sister was like feeding me". Her sister and her husband were also present for chemotherapy appointments which Cathy really appreciated. She said:" We made like a day of it though, like my sister Cookie would come with me and my husband for chemo day". Thus, research findings in this study indicate that family support played a significant role in helping participants cope with their cancer experience both emotionally and to aid with everyday activities like taking them to 
appointments, preparing meals and reminding them to take medication. Cancer patients are in a vulnerable situation and having the support of family was crucial to the recovery of the six participants.

Just as family support was important to the recovery of the women in this study, so was the support of friends and colleagues. All of the women agreed that their friends and coworkers were instrumental in helping them cope with their poor memory. They reminded them of appointments and meetings and supported them throughout the chemotherapy. Sheila, for example, relied on the teachers at work for help and support stating: "I have tons of friends at work". Tina had her coworkers reminding her to leave to go to her chemotherapy appointment.

All participants considered their friends and coworkers to be a part of their extended family outside of the home. Support outside of the home, particularly in the work environment was so important to the participants of this study. These support systems made such an important impact and helped them to maintain some normalcy while going through a stressful period in their lives.

\section{Feeling Grateful}

Despite the array of negative emotions participants experienced, all of them expressed feeling grateful for coming through the cancer experience. For example, although Sherry experienced great distress about many aspects of her cancer trajectory, her emotions towards recovery and getting on with her life changed as a result of her experience,

Sherry was grateful to be able to endure the cancer ordeal and saw her life from a different perspective, and reflected: 
In the grand scheme of things, I'm here, I'm healthy, I'm well, I'm blessed, I'm healed. So in the grand scheme of things, it really isn't like the end of the life. You're gonna get over it; get through it, you know. So that's probably the messages that in the grand scheme of things focus on getting well, focus on being fully available to your family, your friends, your life and then the details and stuff will come, you know.

Because these women felt so grateful about their experience, many of them also expressed learning not to take anything for granted and wanted to give back to others who were newly diagnosed and just beginning the cancer journey. Sherry, for example, made it a goal to spread the word about the importance of self-breast exam, clinical breast exams and getting yearly mammograms. Some of the women she spoke to also ended up with a diagnosis of early breast cancer because she encouraged them to have a mammogram. Another participant, Cathy, helped to raise awareness of breast cancer by participating in a breast cancer fashion show. Carol joined the breast cancer walks to celebrate her cure and to raise consciousness about breast cancer. Julie shared her experience and offered encouragement and support to the patients she worked with at the cancer center. Tina encouraged her coworkers to have yearly mammograms and to do monthly self-breast exams, and Sheila became a constant support for her sister who was newly diagnosed with breast cancer. She commented: "she was there for me and now I want to help her get through it too."

Regarding putting things in proper perspective, Sherry was able to prioritize aspects in life through her cancer and treatment journey and felt that she came out a changed person because of it. She explained learning what was important to her and made time for the things that 
mattered just as the other participants had. In relation to prioritizing aspects in life, Cathy believed that it was critical to help other women that were having difficulty facing breast cancer because she had experienced and survived breast cancer at a young age. She was grateful that she could be there for them, and said: "I try to help women that have been diagnosed...I just spoke to a woman that was just diagnosed and after speaking to her she said she felt better". Giving back because they felt grateful was important to each of the six participating women in this study and was evident in their comments, reactions, and actions. 


\section{CHAPTER VII}

\section{DISCUSSION, IMPLICATIONS AND RECOMMENDATIONS}

The intention of this study was to describe the lived experience of women 50 and under who experienced chemo brain while completing chemotherapy or within 6 months prior to participation. Six women chose to participate in this phenomenological study and were asked to describe their lived experience of chemo brain. Interview sessions were recorded and data was analyzed, and five main themes emerged, (1) struggles with day to day life, (2) fatigue (3) emotions related to diagnosis and treatment, (4) coping and support, and (5) feeling grateful. Within the theme of struggles with day to day life, four sub-themes were identified: (1) memory loss, (2) difficulty with concentration, (3) inability to communicate using writing skills/disorganization of thoughts and words, and (4) keeping track of and management of time. These four sub-themes were related to daily struggles. Participants also described effective resources and coping mechanisms that helped with the struggles day to day that they experienced. The women described their support system through cancer treatment, which in most cases, included family, friends, and co-workers.

\section{Discussion}

Healthcare providers' report inconsistent professional opinions about the assessment of patients' experiences with the cognitive dysfunction associated with adjuvant chemotherapy, even though chemo brain has been reported in up to $90 \%$ of women receiving chemotherapy for breast cancer (Pullens, De Vries, \& Roukema, 2010). These symptoms often affect the ability of women with breast cancer to maintain usual family, career, and community responsibilities 
verifying the need for continued research that increases providers' understanding of this phenomenon. Therefore, it has been a challenge for healthcare providers to efficiently treat chemo brain without learning how to describe, evaluate, and even try to predict chemo brain in breast cancer patients. Bender and Merriman (2014) postulate that chemo brain may be impacted by other factors like lower IQ, less education and advancing age rather than just treatment with chemotherapy and/or hormonal therapy. These authors also stated that mood and functional ability impact cognitive function and reported that if someone reports a decline in cognitive function, they are more likely to also experience worsening mood (Bender \& Merriman, 2014). Thus, the stress, anxiety and depression experienced by cancer patients throughout the treatment process can negatively affect cognitive function (Bender \& Merriman, 2014). This qualitative study found that although the women did not use the terms stress, anxiety or depression, the descriptions of their experience were stress and anxiety. They described having to work harder to complete everyday activities because of chemo brain which in turn caused greater overall stress.

Furthermore, despite the inability to recognize who will get chemo brain or trying to find out how to prevent it, studies have verified that chemo brain is a real phenomenon (Thielen, 2008, Mulrooney, 2007) and needs to be addressed by oncology healthcare providers in order to fully treat those affected by it. Von Ah (2015) discussed the importance of acknowledging the existence of chemo brain to breast cancer survivors who often felt humiliated in social situations because they could not remember important details explaining that although it was difficult to mitigate symptoms of chemo brain, it was important to validate the manifestations of it (Von Ah, 
2015). In this study, research findings corroborate the Von Ah (2015) study as it was found that as in other studies, participants were not told about chemo brain. They heard about it from friends, coworkers or read articles about it. They expressed a desire to have heard about the commonly occurring symptoms of chemo brain from their oncology healthcare provider prior to having it happen to them. They stated that they would have been better able to deal with the consequences of chemotherapy as it related to cognitive decline if they were prepared for it.

The literature supports descriptions of chemo brain as well as symptoms of cognitive dysfunction. The studies of Staat and Segatore (2005), and Jenkins et al., (2006) substantiate the existence of cognitive dysfunction as a result of chemotherapy in breast cancer. Symptoms associated with chemo brain include: complaints of short term memory loss, difficulty concentrating, struggling to make simple decisions, difficulty finding the right words, trouble multi-tasking and feelings of mental dullness (Staat \& Segatore, 2005, Thielen, 2008, Mulrooney, 2007). Findings in this study support these previous results. In relation to difficulty finding the right words, this study found that participants often had difficulty finding words and had to describe a situation to someone in order to help them find the right word. Regarding struggling to make simple decisions, participants in this study mentioned that even simple decisions like whether to have rice or mashed potatoes for dinner was a difficult decision at times. Thus, it is inferred from the amount of information gathered in this investigation that chemo brain is a phenomenon that has considerable impact on the lives of women with early stage breast cancer who have received chemotherapy. 
Literature describes some of the disruptions of life caused by chemo brain such as how cancer and cancer treatment affected participants' ability to work, as well as returning to work after chemotherapy, (Kennedy, Haslam, Munir, \& Pryce, 2007). Kennedy, Haslam, Munir, and Pryce (2007) reported a decrease in overall work productivity and feelings of disappointment for not being able to perform as before cancer treatment in their companies. Similarly, Munir, Burrows, Yarker, Kalawsky, and Bains (2010) found that all 13 breast cancer survivors reported cognitive deficiencies affecting work performance and their ability to return to work. Hede (2008), Von Ah, Haberman, Carpenter and Schneider (2013) found similar results in that participants were reluctant to return to work because of the cognitive problems they faced. Findings in these studies support the idea that returning to work after experiencing chemo brain is difficult. Participants expressed feelings of inadequacy and were reluctant to return to work due to the fear of not being able to perform to the company's standards. Participants also agreed on the importance of returning to a normal life after treatment, but found it difficult to do. The findings of this study are consistent with these studies on 2 major points. Women who have experienced chemo brain struggle emotionally between their desire to return to normalcy in work and a fear of how they will perform on returning to work.

Regarding social aspects and support from others, studies of cancer patients indicate the importance of a support system in which patients could temporarily relinquish responsibilities and allow family and friends to take over until they are able (Thielen, 2008, Mulrooney, 2007) .There are however few qualitative studies on socioemotional aspects and coping or emotional compensation of patients due to chemo brain. In this respect, this research study contributes to 
the limited literature on both cognitive and socioemotional aspects affecting women with cancer and chemo brain. The findings of this study emphasize the need to provide important information on the type of support and specific needs of the participants, which included emotional as well as physical support. Women with cognitive dysfunction as a result of chemotherapy need guidance about what to expect and how to cope with chemo brain. Main themes and subthemes that emerged from this study support previous literature on participants needing guidance which leads to improvement of quality of life. The women in this study offered great examples of all the little ways they coped with chemo brain, which can be shared with other women with the same experience. The excellent strategies used by the women in this study can be offered as a guideline for other women with breast cancer who experience chemo brain. This information is not in the literature and is an important contribution of this study.

Although chemo brain has been reported as neurocognitive changes and cognitive impairment (Thielen, 2008 \& Mulrooney, 2007), the women in this study reported it as more than a change in brain function and therefore cannot be separated from the complete illness experience. These women reported anxiety, fear and overwhelming fatigue along with cognitive decline. When telling their stories, the 6 women included these aspects as part of their experience. One of the women in the study said that she was too tired to take her medication after setting an alarm to remind her to take it.

\section{Limitations}

This study included women 50 and under with early stage breast cancer who experienced chemo brain and is limited to the characteristics of the population studied. Although the women 
represented some cultural and racial diversity, the sample was homogeneous with respect to the sample being all educated women aged 50 and under, and was specifically chosen to help rule out other causes of cognitive dysfunction, for example age-related cognitive decline. These women were busy, high-functioning, and able to multi-task prior to receiving chemotherapy.

The participants in this study included only women since women are more likely to get breast cancer; however, men can also experience breast cancer and have experienced chemo brain. How would their experience be similar or different? Thus, men should be considered in future studies on cognitive impairment as a result of chemotherapy.

\section{Implications for Nursing}

Findings from this study have implications for healthcare in general and nursing practice in particular as they could help to raise awareness and greater understanding about the lived experience of chemo brain in breast cancer survivors. By understanding specific areas of cognitive dysfunction affected by chemotherapy, like memory, concentration, and task completion, the findings of this study provide valuable information to cancer patients, as well as healthcare providers, including nurses. By considering these research based findings, the overall quality of life for patients may improve.

In this study, participants wished that healthcare providers had provided more recognition and understanding of cognitive dysfunction as a result of cancer treatment. Therefore, the counseling and education of women about the side effect of chemo brain should begin during the initial teaching session and should be assessed for throughout each chemotherapy cycle and follow up visit (table 2). 
Table 2. Sign \& symptoms of chemo brain identified in this study.

1. Memory loss

2. Difficulty with concentration

3. Inability to communicate using writing skills/disorganization of thoughts \& words

4. Difficulty keeping track of and managing of time

Providing patients with information and recommending compensatory mechanisms, such as: smartphone applications, notepads, and dry erase boards, should be included in the counseling and education session so that survivors can be prepared with an armamentarium of methods to help combat the decline that they experience as a result of treatment (table 3).

\section{Table 3. Coping mechanisms used by participants in this study.}

1. Post it (sticky) notes

2. Smart phone reminders (calendars, alarms, apps)

3. Support from family \& friends

4. Outlook calendars/email

5. Written notes in plain sight (refrigerator, bathroom mirror) 
With respect to cancer and chemotherapy, learning about side effects including chemo brain should be part of a comprehensive orientation program for all oncology nurses because long term side effects like chemo brain impact survivorship. This was an important finding of this study since none of the participants were told about chemo brain as a possible side effect and stated that they would have liked to have had the information about it from their oncology providers, rather than hearing it from a friend or reading about it in a magazine. Thus, participants in this study found themselves unprepared for cognitive changes as a result of cancer treatment when it happened and would have liked to have had specifics on it, even if no effective treatment exists (table 4).

\section{Table 4. What women wanted to know about chemo brain before beginning chemotherapy.}

1. Chemo brain exists. It is a real phenomenon.

2. Cognitive effects of chemotherapy and how will it change my daily life.

3. What can I do for it?

4. How long will it last?

\section{Recommendations for Future Research}

Future studies can include replication of this study with a larger more diverse population, as well as other types of cancers, in order to gain an overall understanding of chemo brain. Also, following these same women over time and interviewing them 5 and 10 years after completing chemotherapy could present new findings about chemo 
brain over time. By interviewing these women over time, the women may not only see changes in cognitive function, but also in the emotions, like anxiety, that they felt during diagnosis and treatment. Other studies could include a population of only men with breast cancer or for women who receive only hormonal treatment rather than chemotherapy, to see if they have a different with experience cognitive changes. Could the issues related to cognitive changes be related to the cancer diagnosis rather than the treatment? These questions are well worth exploring.

\section{Final Thoughts}

Due to the gaps in the literature surrounding the area of chemo brain in breast cancer, there is limited knowledge available, and thus this phenomenological study helped to generate new information about the experience of chemo brain in early stage breast cancer. Most importantly, this study provided a voice for the women who have had the experience of chemo brain and resulted in rich, thick descriptions of not only the cognitive problems experienced by the women, but also allowed them to describe the effects it had on daily life and how they managed to cope. Their descriptions became part of their transformative journey of having and surviving cancer and will undoubtedly help future breast cancer survivors throughout their treatment process because of the information learned in this study.

Although the goal of this research was to describe the lived experience of chemo brain in early stage breast cancer, the rich descriptions of the symptoms of chemo brain shared by the participating women can help to improve the identification of chemo brain in breast cancer. It is beneficial to identify cognitive impairment as a result of chemotherapy treatment earlier rather 
than later, and although evidence-based interventions remain limited, without proper assessment, interventions that could alleviate symptoms cannot be tried or provided. This has the potential to improve the quality of life for women with chemo brain. 


\section{References}

American Cancer Society. (2015). All about breast cancer. Retrieved from http://www.cancer.org/docroot/HOME/indexA.asp

Bender, C., \& Merriman, J. (2014). Cancer and treatment-related cognitive changes: What can we do now? What lies ahead? Oncology, 28(9), 806-808.

Brezden, C. B., Phillips, K. A., Abdolell, T., Brunston, T., \& Tannock, I. F. (2000). Cognitive function in breast cancer patients receiving adjuvant chemotherapy. Journal of Clinical Oncology, 18(2), 695-701.

Crist, J. D., \& Tanner, C. A. (2003). Interpretation/analysis methods in hermeneutic. Nursing Research, 52, 202-205.

Dowling, M. (2005). From Husserl to van Manen. A review of different phenomenological approaches. International Journal of Nursing Studies, 44, 131-142.

Frank, J. S., Vance, D. E., Jukkala, A., \& Meneses, K. M. (2014). Attention and memory deficits in breast cancer survivors: Implications for nursing practice and research. Journal of Neuroscience Nursing, 46(5), 274-284.

Frits, S., van Dam, W., Schagen, S., Muller, M., Droogleever Fortuyn, M., Wall, E., \& Rodenhuis, S. (1998). Impairment of cognitive function in women receiving adjuvant treatment for high-risk breast cancer: High-dose versus standard-dose chemotherapy. Journal of the National Cancer Institute, 90(3), 210-218.

Gazzaley, A. (n.d.). Normal aging. Retrieved from http://memory.ucsf.edu/Education/ Topics/normalaging.html

Giorgi, A. (1985). Phenomenology and psychological research. Pittsburgh, PA: Duquesne University.

Grober, S. (2002). Resources for treatment of chemotherapy-related cognitive difficulty. Cancer Practice, 10(4), 216-218.

Harvard Health Publications. (2002). Cognitive problems after chemotherapy for breast cancer. Harvard Women's Health Watch, 10(2), 5-6.

Hede, K. (2008). Chemobrain is real but may need new name. Journal of the National Cancer Institute, 100, 162-169. 
Heidegger, M. (1962). Being and time. San Francisco, CA: Harper and Row.

Hess, L., \& Insel, K. (2007). Chemotherapy-related change in cognitive function: A conceptual model. Oncology Nursing Forum, 34(5), 981-994.

Higginbottom, G. (2004). Sampling issues is qualitative research. Nurse Researcher, 12(1), 7-19.

Husserl, E. (1965). Phenomenology and the crisis of philosophy. Philadelphia, PA: Harper and Row.

Inagaki, M., Yoshikawa, E., Matsuoka, Y., Sugawara, Y., Nakano, T., \& Akechi. (2007). Smaller regional volumes of brain gray and white matter demonstrated in breast cancer survivors exposed to adjuvant chemotherapy. Cancer, 109(1), 146-156.

Janelsins, M., Heckler, C., Peppone, J., Kamen, C., Mustian, K., Mohile, S., Magnuson, A., Kleckner, I., Guido, J., Young, K., Conlin, A., Weiselberg, L., Mitchell, J., Ambrosone, C., Ahles, T., \& Morrow, G. (2017). Cognitive complaints in survivors of breast cancer after chemotherapy compared with age-matched controls: An analysis from a nationwide, multicenter, prospective longitudinal study. Journal of Clinical Oncology, 35(5), 506514.

Jansen, C., Miaskowski, C., Dodd, M., \& Dowling, G. (2007). A meta-analysis of the sensitivity of various neuropsychological tests used to detect chemotherapy. Oncology Nursing Forum, 34(5), 997-1005.

Jansen, C., Miaskowski, C., Dodd, M., Dowling, G., \& Kramer, J. (2005). Potential mechanisms for chemotherapy-induced impairments in cognitive function. Oncology Nursing Forum, 32(6), 1151-1163.

Jenkins, V., Shilling, V., Deutsch, G., Bloomfield, D., Morris, R., \& Allan, S. (2006). A 3-year prospective study of the effects of adjuvant. British Journal of Cancer, 94, 828-834.

Kennedy, F., Haslam, C., Munir, F., \& Pryce, J. (2007). Returning to work following cancer: A qualitative exploratory study into the experience of returning to work following cancer. European Journal of Cancer Care, 16, 17-25.

Lincoln, Y., \& Guba, E. (1985). Naturalistic Inquiry. Newbury Park, CA: Sage.

Merlau-Ponty, M. (1962). Phenomenology perception. (1962). London, UK: Routledge and Kegan Paul. 
Meyers, C. (2013). Cognitive complaints after breast cancer treatments: Patient report and objective evidence. Journal of the National Cancer Institute, 105(11), 761-762.

Mulrooney, T. (2007). The lived experience of cognitive impairment in women treated with chemotherapy for breast cancer (Doctoral dissertation). Retrieved from University of Utah Spencer S. Eccles Health Sciences Library. (Accession No. 193692).

Munhall, P. (2007). Nursing research: A qualitative perspective ( $4^{\text {th }}$ ed.). Boston, MA: Jones and Bartlett.

Munir, F., Burrows, J., Yarker, J., Kalawsky, K., \& Bains, M. (2010). Women's perceptions of chemotherapy-induced side affects on work ability: A focus group study. Journal of Clinical Nursing, 19, 1362-1370.

National Institutes of Health. (1979). The Belmont report. Ethical principles for the protection of human. Retrieved from: http://ohsr.od.nih.gov/guidelines/belmont.html\#top

Olin, J. (2001). Cognitive function after systemic therapy for breast cancer. Oncology, 15, 613618.

Paraska, K., \& Bender, C. (2003). Cognitive dysfunction following adjuvant chemotherapy for breast cancer: two case studies. Oncology Nursing Forum, 30(3), 473-478.

Pullens, M., J., De Vries, J., \& Roukema, J. A. (2010). Subjective cognitive dysfunction in breast cancer patients: A systematic review. Psycho-Oncology, 19(11), 1127-1138.

Oncology Nursing Society (2005). Research agenda. Retrieved from http://http://www.ons.org/research/information/documents/pdfs/agenda05.pdf

Rust, C., \& Davis, C. (2013). Chemobrain in underserved African American breast cancer survivors: A qualitative study. Clinical Journal of Oncology Nursing, 17(2), 29-34.

Sandelowski, M. (1986). The problem of rigor in qualitative research. Advances in Nursing Science, 8(3), 27-32.

Sandelowski, M. (1993). Rigor or rigor mortis: The problem of rigor in qualitative research. Advances in Nursing Science, 16(2), 1-8.

Silberfarb, P. M., Philbert, D., \& Levine, P. M. (1980). Psychosocial aspects of neoplastic disease: II. Affective and cognitive effects of chemotherapy in cancer patients. American Journal of Psychiatry, 137, 597-601. 
Staat, K., \& Segatore, M. (2005). The phenomenon of chemo brain. Clinical Journal of Oncology Nursing, 9(6), 713-721.

Thielen, J. (2008). The experience of neurocognitive changes in women undergoing chemotherapy for breast cancer (Doctoral dissertation). Retrieved from DigitalCommon@UConn. (Accession No. AAI3308251).

U. S. Department of Health and Human Services. (2017). Healthy people 2020: What are the goals. Retrieved from http://www.healthypeople.gov/About/goals

van Dam, F., Schagen, S., Muller, M., Boogerd, W., Wall, E., Droogleever Fortuyn, M., \& Rodenhuis, S. (1998). Impairment of cognitive function in women receiving adjuvant treatment for high-risk breast cancer: High-dose versus standard-dose chemotherapy. Jounrnal of the National Cancer Institute, 90(3), 210-218.

van Manen, M. (1990). Researching lived experiences. Ontario, Canada: Althouse Press.

van Manen, M. (1997). Researching lived experience: Human science for an action sensitive pedagogy ( $2^{\text {nd }}$ Ed.). Ontario, Canada: Althouse Press.

van Manen, M. (2002). Writing in the dark: Phenomenological studies in interpretive inquiry. London, UK: Althouse Press.

Von Ah, D. (2015). Cognitive changes associated with cancer and cancer treatment: State of the science. Clinical Journal of Oncology Nursing, 19(1), 1-10.

Von Ah, D., Haberman, B., Carpenter, J., \& Schneider, B. (2013). Impact of perceived cognitive impairment in breast cancer survivors. European Journal of Oncology Nursing, 17, 236241.

Von Ah, D., Jansen, C., \& Allen, D. (2014). Evidence-based interventions for cancer-related and treatment-related cognitive impairment. Clinical Journal of Oncology Nursing, 18(6), 1725 .

Weineke, M. H., \& Dienst, E. R. (1995). Neuropsychological assessment of cognitive functioning following chemotherapy for breast cancer. Psycho-Oncology, 4, 61-66. 
Appendix A

\section{Methodological Outline for Doing Phenomenology (van Manen, 1997, p. 5)}

A) Turning to the nature of the lived experience

1. Orient to the phenomenon of interest

2. Formulate the phenomenological question

3. Explicating assumptions and preunderstandings

B) Investigating the experience as we live it in everyday as opposed to conceptualizing it;

4. Explore the phenomenon: generate "data"

4.1 Use personal experience as a starting point

4.2 Trace etymological sources

4.3 Search idiomatic phrases

4.4 Obtain experiential descriptions from subjects

4.5 Locating experiential descriptions in literature, art, poems, etc.

5. Consult phenomenological literature

C) Phenomenological Reflection

6. Conduct thematic analysis

6.1.1 Uncover thematic aspects in lifeworld descriptions

6.1.2 Isolating thematic statements

6.1.3 Composing linguistic transformation

6.2 Gleaning thematic descriptions from artistic sources 
7. Determine essential themes

D) Phenomenological Writing

8. Attending to the speaking of language

9. Varying the examples

10. Writing

11. Rewriting 


\section{Appendix B}

\section{Flyer}

Are you a woman with breast cancer who has experienced chemo brain?

(Chemo brain refers to cognitive changes associated with chemotherapy treatment that is manifested by an inability to concentrate, remember details, \& complete familiar tasks as quickly as you may have prior to treatment.)

If you are 50 and under, have early stage breast cancer (I or II) and have completed chemotherapy treatment in the last six months and would like to participate in a research study describing your experience with chemo brain, please contact me at:

\section{Patricia Gibbons}

\section{Gibbonpa@shu.edu}

or

call Sharon Venino, Assistant to the Ph.D. Program, College of Nursing, Seton Hall University, at (973) 313-6040 and she will forward your message to me and I will contact you as soon as possible.

I am a PhD nursing student at Seton Hall University working on my dissertation and your participation in this study will help to increase knowledge about the lived experience of chemo brain in early stage breast cancer. Participation is voluntary and there is no monetary compensation for participating. 


\section{Appendix C}

\section{Consent Form}

\section{Researcher's Affiliation}

Patricia A. Gibbons is a doctoral candidate at Seton Hall University College of Nursing.

\section{Purpose}

The purpose of the dissertation research is to describe and understand the lived experience of chemo brain in women with early stage breast cancer who are receiving or have received chemotherapy within the last six months.

Participants are being asked to participate in this study because they have identified themselves as having had the experience of chemo brain after receiving chemotherapy treatment for early stage breast cancer and are age 50 or under. They are now receiving or have completed treatment within the last six months.

\section{Duration/Procedures}

The study involves 2-3 interviews that will last approximately 1-2 hours, but may last as long as 3 hours depending on the participant's desire to continue. The interviews will be at a location and a time of the participant's choice, that will allow for an uninterrupted, private dialogue between them and Patricia A. Gibbons. The interviews will be audio taped and 
transcribed verbatim by Patricia A. Gibbons. Participants will be asked to answer questions that describe their experience with receiving chemotherapy and about their experience with chemo brain for example, "What is chemo brain like for you" and "How did the experience of chemo brain impact your life on a daily basis?" Participants will also be asked to provide examples of their experience with chemo brain.

\section{Voluntary Nature}

Participation in this study is completely voluntary. Participants may withdraw from this study at any time, without reprisal.

\section{Confidentiality/Anonymity}

Overall results from this study will be published in the aggregate. Confidentiality will be maintained and upheld. Although participants will not be anonymous to the researcher, their names will be changed so that no one else will know their identity. Only the researcher and Dr. Judith Lothian, Dissertation Chair, will have access to the field notes, audio tapes, and transcriptions.

\section{Records}

All data will be kept in a secured locked cabinet to which only the researcher will have access. Identity of participants will not be disclosed on any field notes, audio tapes, or transcriptions.

\section{Risks/Discomforts}


There are no anticipated risks or benefits to participating in this study. In the event that interviews cause psychological distress, participants will be referred to local breast cancer support groups.

\section{Compensation}

There is no cost to participants for participating in this study except their time. Funding for this study will be the responsibility of the researcher and participants will not be paid for their participation.

\section{Contact Information}

Participants are encouraged to ask any question about this research study now or in the future. Questions can be directed to Patricia A. Gibbons via email at gibbonpa@ shu.edu, through Sharon Venino, Administrative Assistant to the College of Nursing, Ph.D. Program at Seton Hall University at (973) 313-6040, or participants may contact the Dissertation Chair for this study, Dr. Judith Lothian at (973) 761-9273. If participants have any questions regarding their rights as a participant in this study, please contact Mary Ruzicka, Ph.D., Director of Seton Hall University IRB, at (973) 313-6314. Participants will be given a copy of this signed consent form for their records at the time of the first interview.

$\mathrm{I}$, hereby authorize my participation in the research study on the lived experience of chemo brain in women with early stage breast cancer after chemotherapy and I 
consent to be audio taped. I have read the risks of this study, and I understand that I can withdraw from this study at any time, without reprisal.

Signature of Participant

Date

Sincerely,

Patricia A. Gibbons, MSN, RN, AOCN 


\section{Appendix D}

\section{Letter of Invitation}

I am in the Ph. D. Program, at Seton Hall University College of Nursing. My dissertation is a qualitative research study of the lived experience of chemo brain in women 50 and under during or after receiving chemotherapy for early stage breast cancer.

Because you have had the experience of chemo brain, you are being invited to participate in this study. The study requires your participation in several audio taped interviews with me. The interviews will last approximately 1-2 hours. I would like to interview you 2-3 times. Examples of interview questions that may be included are, "Tell me about your experience with chemo brain," and "Share with me how this has affected your daily life."

Your participation in this research is completely voluntary and there is no penalty if you do not participate. Although you will not be anonymous to me, no one else will know your identity. Specifically, you will be given a pseudonym so that your identity will not be known to anyone except me. All transcribed interviews will be confidential and kept secure in a locked drawer to which only I have access.

I invite you to review the information. If you are willing to participate, we will make arrangements to return your signed Consent Form to me. I will personally telephone you as soon as I receive your signed consent form to answer any questions to discuss your participation and 
arrange for the first interview. If you have any questions, before or while you are reviewing the documents, please call Sharon Venino, Assistant to the Ph.D. Program, College of Nursing, Seton Hall University, at (973) 313-6040 and she will forward your message to me and I will contact you as soon as possible. If you prefer, you can reach me via email at gibbonpa@ shu.edu. I look forward to hearing from you.

Sincerely,

Patricia A. Gibbons, MSN, RN, AOCN 
Appendix E

\section{Permission to Invite Potential Participants at Local Oncology Practices}

Dear Doctor/Oncology Nurse:

I am a Ph.D. candidate, at Seton Hall University College of Nursing. For my dissertation research, I plan to conduct a qualitative study to describe and understand the lived experience of chemo brain in women 50 and under with early stage breast cancer after chemotherapy.

The purpose of this letter is to ask you to help me recruit volunteers for my research study. I would ask you to put up a flyer somewhere in your office where it would be visible to potential participants. The flyer explains the purpose of my study, criteria for participation and my contact information.

If you have any questions, you can reach me at gibbonpa@ shu.edu or you may contact Sharon Venino, Administrative Assistant to the Ph.D. Program, Seton Hall University College of Nursing at (973) 313-6040. Mrs. Venino will forward your message to me and I will contact you as soon as possible.

Thank you.

Sincerely,

Patricia A. Gibbons, MSN, RN, AOCN 


\section{Appendix F}

\section{Permission to Speak to Local ONS Chapters}

ONS Chapter President

Dear ONS Chapter President:

I am a Ph.D. candidate, at Seton Hall University College of Nursing. For my dissertation research, I plan to conduct a qualitative study to describe and understand the lived experience of chemo brain in women 50 and under with early stage breast cancer after chemotherapy in the private practice setting.

The purpose of this letter is to request an opportunity to address members of the local chapter of ONS during a regularly scheduled meeting in order to explain the purpose of my study and request that information be passed on to potential volunteers who may be interested in participating in this study. I will need approximately fifteen minutes time to discuss the study purpose and to answer members' questions, as well as requirements for participation in the study. I also plan to distribute written information about the study and documents that the members can distribute to potential participants.

An important part of the Seton Hall University IRB application is that the researcher demonstrates prior planned access to potential participants for the study being proposed. Therefore, because I must provide the SHU IRB with a Letter of Permission from those organizations from which I will seek potential study participants, I am also asking you to forward to me, a letter agreeing to allow me to address the membership of ONS for the purpose of seeking participants for my research study. Because I value your time, I am enclosing a form letter, indicating your agreement to my request to address members at the ONS that meets the above SHU IRB requirement. 
Please accept my thanks in advance, for your consideration of my requests as outlined in this letter. In summary, I am a.) Requesting permission to address the ONS local chapter members at a regularly scheduled meeting, b.) Per SHU requirement, requesting your letter of permission to attend an ONS/NJ meeting to discuss my research. If you agree, and for your convenience, I have attached a sample letter for you to sign and return it in the self addressed stamped envelope by May 5, 2010.

If you have any questions, you can reach me at Gibbonpa@shu.edu or you may contact Sharon Venino, Administrative Assistant to the Ph.D. Program, Seton Hall University College of Nursing at (973) 313-6040. Mrs. Venino will forward your message to me and I will contact you as soon as possible.

Thank you, again.

Sincerely,

Patricia A. Gibbons, MSN, RN, AOCN 


\section{Appendix G}

\section{Support Groups}

\section{Westchester}

In the Pink

PO Box 285

Eastchester, NY 10708

914-318-4090

inthepinkinfo@aol.com

Gilda's Club Westchester

80 Maple Avenue

White Plains, NY 10601

914-644-8844

\section{New York City}

Share

1501 Broadway, Suite 704A

New York, NY 10036

212-719-0364

Gilda's Club Worldwide 
322 Eighth Avenue, Suite 1402

New York, NY 10001

888-445-3248

Young Survival Coalition

61 Broadway, Suite 2235

New York, NY 10006

877-972-1011

Other Resources

American Cancer Society

800-227-2345 


\section{Appendix H}

\section{Interview Guideline/Outline}

1. Tell me a little bit about yourself?

2. Describe your experience with receiving chemotherapy and chemo brain.

3. Share with me some examples of chemo brain.

1. How did having the experience of chemo brain impact your life on a daily basis? 